\title{
Cerámicas importadas del Sector G de La Serreta (Alcoi-Cocentaina- PENÀGUILA). REPERTORIO, DISTRIBUCIÓN Y COMENSALIDAD EN UNA CIUDAD CONTESTANA
}

\author{
Imported pottery from the Sector G of La Serreta (Alcoi-Cocentaina-Penàguila, Spain). Repertoire, distribu- \\ tion and commensality in a Contestanian city
}

\section{IVÁN AMORÓS LÓPEZ}

Instituto Universitario de Investigación en Arqueología y Patrimonio Histórico (INAPH). Universidad de Alicante. ivan.amoros@ua.es (https://orcid.org/0000-0003-4791-3248)

RESUMEN:

En este trabajo presentamos un conjunto inédito de cerámicas importadas del denominado Sector G del poblado ibérico de La Serreta de Alcoi, recuperadas en las excavaciones del año 1968. El conjunto está compuesto por un repertorio variado que incluye desde ánforas a vajilla de mesa de barniz negro, abarcando un periodo amplio de tiempo entre los ss. V-IV a.C. y el III a.C. Es precisamente esta última fase la que resulta más interesante, ya que ha sido posible reconocer los contextos y establecer una distribución por departamentos. A partir de todos estos datos, podemos proponer algunas interpretaciones de carácter social que nos aproximan a cuál pudo ser la relevancia y el papel de estos bienes importados en una ciudad ibérica del s. III a.C.

Palabras clave: cerámica importada, cultura ibérica, II Edad del Hierro, Contestania, comensalidad.

\section{Abstract:}

In this paper, we present an unpublished set of imported potteries from the so-called Sector $G$ of the Iberian town of La Serreta de Alcoi, recovered in the 1968 s excavations. This set is formed by a varied repertoire, from amphorae to black glazed tableware, covering a wide period between the 5th-4th and 3rd centuries BC. This last phase is highly interesting, since it has been possible to recognize the contexts and establish a distribution by areas. Considering this data, we propose some social interpretations that bring us closer to the relevance and the role of these imported goods in a $3 r d$ century BC Iberian city.

Key words: imported pottery, Iberian culture, Iron Age II, Contestania, commensality. 
El estudio de las cerámicas importadas ha atraído tradicionalmente la atención de los investigadores ya desde los primeros tiempos de la constitución de la arqueología como disciplina científica. Esta aproximación ha tenido lugar desde perspectivas e intereses diversos, desde los arduos análisis tipológicos y sus derivaciones de carácter cronológico, tan importantes a la hora de datar nuestros contextos, al estudio de los centros de producción o redes de intercambio, es decir, aspectos más económicos. Por otra parte, en los últimos tiempos se está valorando también la importancia de este tipo de vajillas y productos importados en sus contextos de uso, teniendo en cuenta su papel en el marco de las relaciones sociales de los grupos ibéricos. Estos objetos pueden ser entendidos desde un punto de vista ideológico, como bienes de prestigio con un rol protagonista en diversas prácticas con un cierto componente ritualizado que ayudan a construir, consolidar o legitimar las relaciones sociales de poder o desigualdad en el seno de estas comunidades, principalmente a través de lo que conocemos con el nombre de comensalidad (Diloli y Sardà 2009; Sardà 2010; Mata et al. 2010).

Precisamente siguiendo esta última línea de investigación hemos publicado en fechas recientes algunos trabajos donde analizamos este tipo de prácticas de comensalía y donde tienen un papel muy destacado estas cerámicas importadas por ser susceptibles de ser tratadas como un elemento diacrítico (Amorós 2019a; 2019b). En estos trabajos, y siempre basándonos en el diálogo entre las distintas escalas de observación o análisis, dimos una mayor importancia a la perspectiva territorial porque nos parecía interesante hablar de un "paisaje de la comensalidad", en la medida en que las prácticas sociales tienen una dimensión espacial, con su evolución y matices en tres territorios cercanos pero cada uno con sus peculiaridades y en un periodo dilatado de tiempo. En este caso, en cambio, queremos profundizar un poco más en la segunda escala de análisis, la que tiene en cuenta los contextos de aparición de este tipo de cerámicas, su distribución en lugares de hábitat o la proporción con respecto a otro tipo de producciones. Este tipo de análisis no siempre es posible debido a la falta de contextos fiables o a la adscripción de estos objetos a un determinado departamento o no digamos ya unidad estratigráfica en las excavaciones antiguas.

Con este objetivo, creemos que uno de los casos en los que es posible aproximarse a estos contextos con ciertas garantías es el poblado ibérico de La Serreta ubicado al $\mathrm{N}$ de la provincia de Alicante, entre los términos de Alcoi, Cocentaina y Penàguila en lo que se viene denominando como área central de la Contestania, en la unidad geográfica de los Valles de Alcoi (fig. 1). La historia de la investigación en este importante yacimiento ibérico, que se ha convertido en uno de los referentes para el estudio de la cultura ibérica, ha sido tratada de forma amplia en otras publicaciones anteriores, a las que remitimos al lector interesado (Llobregat et al. 1992; Grau et al. 2017).

El conjunto arqueológico está compuesto por el poblado, el santuario y la necrópolis. En cuanto al hábitat, podríamos definirlo como un oppidum o poblado fortificado en altura con una larga perduración en el tiempo, ya que existen evidencias que se remontarían a los ss. VII-VI

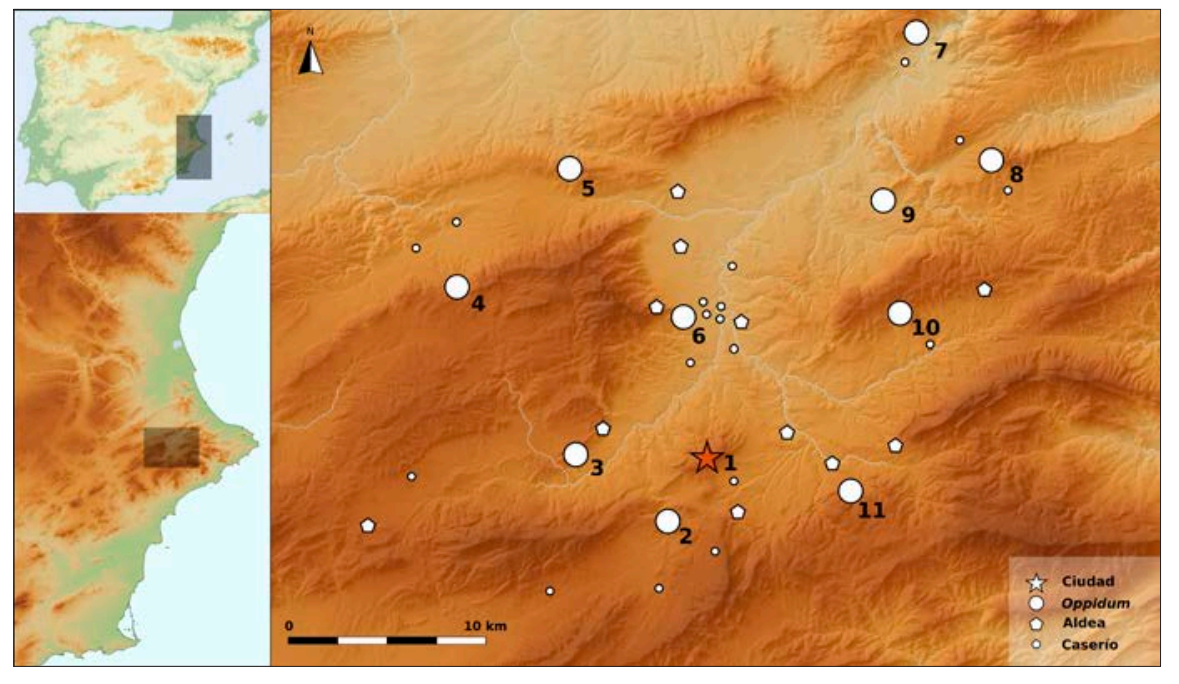

Fig. 1: Mapa de situación de La Serreta (1) y poblamiento en los ss. IV y III a.C. Oppida: 2. El Puig, 3. Castellar, 4. Cabeçó de Mariola, 5. Covalta, 6. Castell de Cocentaina, 7. Castell de Perputxent, 8. Xarpolar, 9. Ermita de Planes, 10. Pitxòcol, 11. Castell de Penàguila. Elaboración propia a partir de Grau et al. 2017: fig. 6.1). 
Fig. 2: Plano general de La Serreta con los distintos sectores. Planta del Sector G con la numeración de los departamentos. Elaboración propia a partir de la planimetría de Llobregat (1972) y de Llobregat et al. (1992).

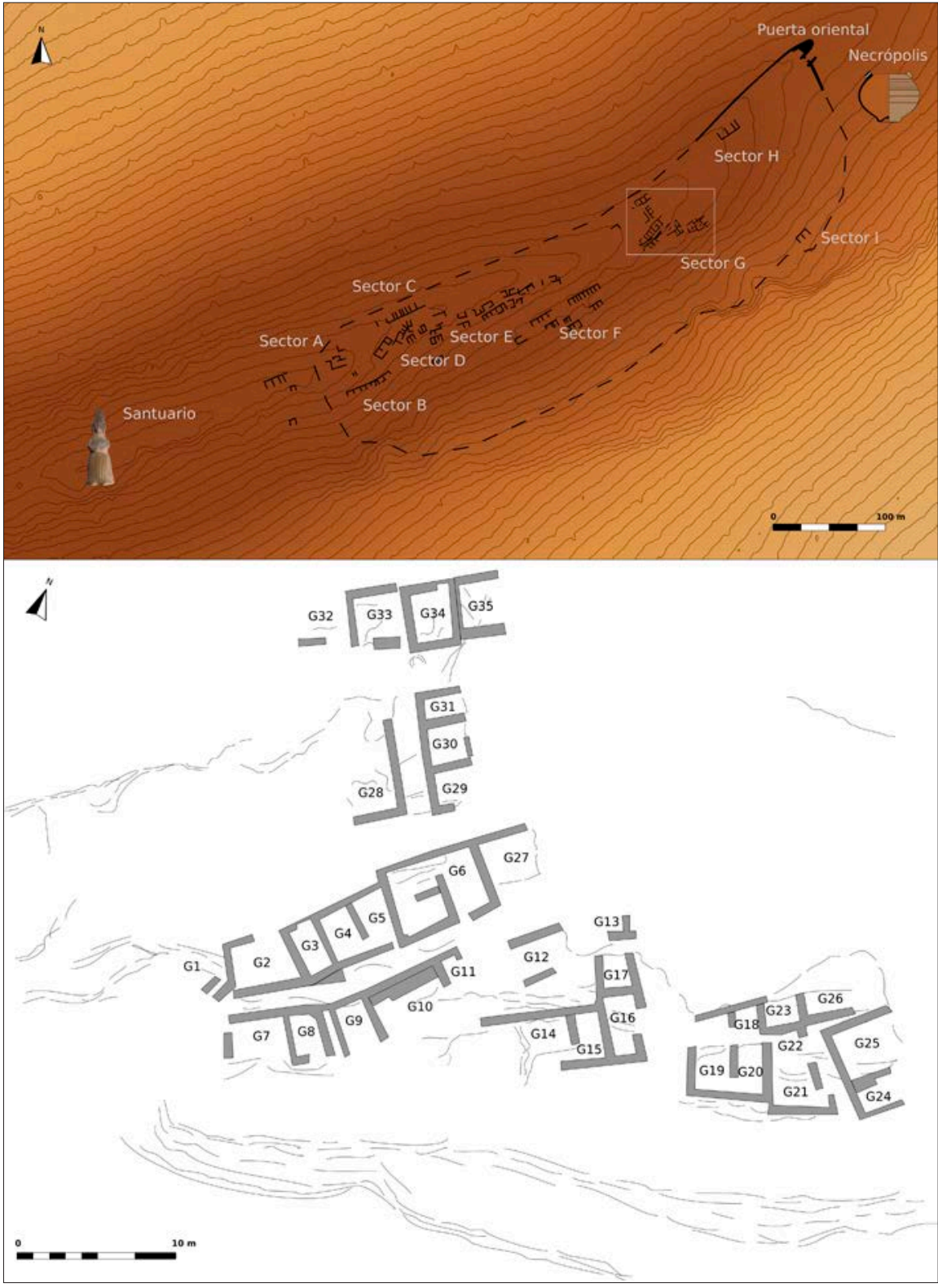

hasta su abandono a finales del s. III a.C. como consecuencia de la Segunda Guerra Púnica. A esta última centuria es a la que corresponden la práctica totalidad de las estructuras de hábitat documentadas, ya que constituye su momento de máximo esplendor cuando se convierte en la capital del territorio comarcal con una extensión de unas 6 ha. La ciudad se caracteriza en estos momentos por un urbanismo aterrazado, que se adapta a la orografía del terreno y una potente muralla y puerta fortificada en sus puntos más vulnerables (Llobregat et al. 1992; 1995; Olcina et al. 1998).

\section{EL SECTOR G}

El urbanismo del poblado de La Serreta (Llobregat et al. 1992) se basa en su adaptación a la orografía del cerro en el que se ubica, repartiéndose las estructuras de hábitat por la parte más alta y a lo largo de la ladera meridional, ocupando los rellanos naturales entre escarpes rocosos, en ocasiones con cierto acondicionamiento y conformando distintas terrazas. Una vía principal transcurre por la parte más alta del poblado y recorre todo el espacio de hábitat, iniciándose en la puerta oriental fortificada en el 
punto más accesible, mientras que se documenta una calle secundaria, paralela a esta, y a una cota algo más baja. Junto a estas dos vías, existe toda una serie de pequeñas calles, tanto paralelas como perpendiculares a estas, que da lugar a la individualización de diversos conjuntos o sectores con denominaciones correlativas que van de la letra A a la H (Llobregat et al. 1992) (fig. 2). Uno de estos sectores, en concreto el G, será el que ocupe nuestra atención en este trabajo.

Dicho sector fue excavado por el Laboratorio de Arqueología de la Universidad de Valencia a lo largo de dos campañas durante el verano y el otoño de 1968 bajo la dirección de M. Tarradell y con la colaboración de E. Llobregat y V. Pascual. Lo que las hace tan interesantes para nuestros objetivos es la existencia de una detallada planimetría elaborada por E. Llobregat en 1969 (Llobregat 1972: 54) en la que nos basamos para nuestra propuesta, complementada con la topografía de los años 80 (Llobregat et al. 1992). Además, es posible asociar la gran mayoría de los materiales recuperados en dichos trabajos a departamentos muy concretos, que los propios excavadores numeraron del número 1 al 35, a diferencia de lo que sucede en el resto de los sectores intervenidos durante excavaciones antiguas, donde resulta mucho más difícil dicha contextualización.

El Sector G estaría constituido por un grupo de viviendas en la parte occidental de una zona relativamente regular cercana a la entrada natural del poblado y se encuentra delimitado al norte por el derrumbe de la muralla $\mathrm{y}$ al sur por un escarpe rocoso (fig. 2). En la parte $\mathrm{N}$ se encuentran cuatro departamentos alineados (G32-G35) entre la muralla y la vía principal. Una calle perpendicular a esta separa otros dos grupos, el G28 a un lado y el G29-G31 a otro. Adaptándose a la ladera se encuentra otra batería de estancias (G1-G6 y G27) cuyos muros traseros dan a una calle paralela a la principal. Otra calle longitudinal lo separa de otro conjunto conformado por los departamentos G7-G11. A dos niveles diferentes se encuentran otras dos agrupaciones (G12, G13 y G17 y G14-16) y finalmente otra manzana (G18-G26) separada de la anterior por una calle en parte excavada en la roca. Dentro de este abigarrado conjunto parecen intuirse un par de callejones más. Delante de estos grupos de estancias se extiende un espacio abierto sin construcciones a lo largo de la terraza.

A nivel cronológico y pese a que la excavación no siguió unos planteamientos estrictamente estratigráficos, sí parecen identificarse por parte de sus excavadores al menos dos fases distintas, la más antigua de ellas denominada como Serreta I, sin estructuras conservadas pero deducida a partir de materiales y de niveles de relleno para el acondicionamiento de las estructuras del s. III a.C. (Tarradell 1969). Un buen reflejo de ello lo encontramos en el significativo lote de cerámicas áticas tanto de barniz negro como de figuras rojas datadas en los ss. V-IV a.C. que no es posible asociar de forma directa con las estructuras conservadas, que corresponderían a la fase del s. III a.C. El oppidum de esta fase se circunscribiría a la parte más alta del cerro, ya que estas cerámicas griegas no se han hallado en los sectores ubicados en cotas más bajas como el F (Grau 1996) o el I (Olcina et al. 2000).

\section{BREVES APUNTES METODOLÓGICOS}

Como ya hemos expresado, somos conscientes de la importancia de la combinación de las diferentes escalas de análisis a la hora de valorar este tipo de elementos en las sociedades ibéricas. Por ello, comenzamos con el análisis pormenorizado de los objetos realizando un inventario de los productos importados presentes en el Sector G, atendiendo a las formas y producciones documentadas y a su cronología. A la hora de abordar el estudio no nos hemos limitado únicamente a los productos foráneos, sino que hemos ampliado la revisión a todos los materiales incluyendo la cerámica ibérica, los metales, el hueso trabajado o las herramientas líticas con el objeto de contar con una visión más amplia. No obstante, el estudio detallado de todo este amplio conjunto de materiales será publicado en un futuro.

El inventario de los materiales se ha realizado atendiendo al número mínimo de individuos (N.M.I.) (Orton et al. 1997; Arcelin y Tuffreau-Libre 1998; Husi 2001) a partir del recuento de los diferentes bordes correspondientes a cada tipo en primer lugar, pasando a contabilizar las bases en caso de no haber evidencias de los anteriores o, en último lugar, al número de asas divididos entre dos en caso de ausencia de todas las partes anteriores. Para establecer la distinción entre distintos individuos dentro de la misma forma, atendemos a matices tipológicos o diferencias en pastas y barnices.

Una vez explicitado el repertorio formal, procedemos a establecer su distribución entre los 35 departamentos que constituyen el Sector G, teniendo también en cuenta la proporción que se da en cada uno de ellos entre el N.M.I. de cerámicas importadas e ibéricas o las categorías 
Cerámicas importadas del Sector G de La Serreta (Alcoi-Cocentaina-Penàguila). REPERTORIO, DISTRIBUCIÓN Y COMENSALIDAD EN UNA CIUDAD CONTESTANA

funcionales (Sanmartí y Asensio 2017). Con el objeto de proponer algunas interpretaciones de carácter social, será necesario realizar una valoración crítica de los datos, tratando al mismo tiempo de establecer una comparativa con el resto de sectores conocidos de la propia Serreta, o con otros poblados en momentos anteriores para tener una perspectiva algo más diacrónica.

También será necesario tener en cuenta cómo se ha formado el registro, ya que los materiales cuya distribución vamos a analizar son aquellos correspondientes a la última fase de vida del poblado, que se abandona de forma más o menos repentina a finales del s. III o inicios del II a.C. Por tanto, cabría suponer que estos serían los ajuares domésticos en uso en el momento del abandono, cuya buena conservación se ha visto favorecida por la ausencia de ocupaciones posteriores en el cerro. No obstante, los procesos postdeposicionales, como la erosión, han afectado de forma desigual a las distintas estancias dependiendo de su ubicación en el área que ocupa este barrio.

La última fase de la investigación es la que tiene que ver con esta interpretación desde un punto de vista social y el papel que estos elementos importados pueden estar desempeñando como marcadores sociales entre las comunidades ibéricas objeto de nuestro estudio. En este sentido, resulta muy útil una aproximación a este tipo de objetos desde el prisma de la comensalidad, aunque dichas prácticas no engloben únicamente elementos foráneos. Podríamos definirla como el consumo comunal de comida y bebida como una forma de actividad ritualizada para un propósito u ocasión especial y diferenciadas del consumo cotidiano (Dietler y Hayden 2001). En esta misma línea, entra en juego el concepto de intercambio de dones o regalos, más relacionado con elementos diacríticos (Godelier 1998) o la redistribución de bienes de prestigio (Sanmartí 2009) que genera una serie de obligaciones recíprocas y deudas entre donante y receptor que pueden ser manipuladas para la obtención de diversas ventajas sociales.

Algunos de estos bienes de prestigio podrían ser considerados como elementos diacríticos, basándonos en el concepto de diacritical insignia de M. Dietler (1999: 146). Se trata de bienes con una función simbólica importante, utilizados como indicadores de estatus, cuyo principal uso es el de ser acumulados, exhibidos y consumidos y que no se incluirían entre los productos básicos y los circuitos de intercambio. No obstante, dichos productos habrían sido a menudo adquiridos inicialmente a través del intercambio de regalos con fuentes externas y pueden ser intercambiados de forma restringida entre las comunidades locales. Este autor propone una distinción entre este tipo de productos, de circulación más limitada, y los denominados bienes de intercambio destinados a la redistribución.

Para estos objetivos, resulta esencial reconocer el modo en que dichas prácticas se materializan y se plasman en el registro arqueológico y su análisis desde diversas escalas de observación. La elección de este tipo de objetos importados se debe a su especial relevancia como elementos potencialmente ritualizables, difíciles de adquirir y que requieren en muchas ocasiones unos conocimientos para su "correcta" utilización, ya se trate de los propios recipientes y vajillas o, de forma indirecta, de los alimentos consumidos, valorados por su escasez, sabor o propiedades psicoactivas. Esta primera escala de análisis, debe ser complementada con una valoración de los contextos arqueológicos con el fin de establecer asociaciones entre los repertorios, análisis espaciales, relación con estructuras arquitectónicas y análisis cuantitativos. Igual de importante resulta la tercera unidad de observación referida al paisaje, que tiene un menor peso en este trabajo, pero que, como ya hemos indicado, ha tenido un mayor protagonismo en otros trabajos anteriores, a los que también remitimos para un tratamiento más extenso de cuestiones teóricas y metodológicas, así como de los mecanismos y estrategias relacionados con la comensalidad (Amorós 2019a; 2019b).

\section{EL REPERTORIO DE IMPORTACIONES DEL SECTOR G}

Procedemos en este apartado a presentar el conjunto de importaciones recuperadas en este sector del poblado, estableciendo una primera subdivisión entre categorías funcionales con un primer apartado dedicado a las ánforas, seguido de uno más extenso referente a la vajilla de mesa, para finalizar con una categoría casi testimonial como son las cerámicas de cocina y un apartado de otros recipientes no relacionados a priori con prácticas de comensalidad (fig. 3). Para la denominación hemos recurrido a la tipología de J. Ramon (1995) con algún matiz, como veremos, para el caso de las ánforas, mientras que para las cerámicas finas hemos optado en la mayoría de los casos por la denominación establecida por N. Lamboglia (1952), conscientes de que en muchos aspectos ha 


\begin{tabular}{|c|c|c|c|c|}
\hline Producción & Tipo & N. M. I. & $\%$ & Cronología \\
\hline \multicolumn{5}{|c|}{ ÁNFORAS } \\
\hline $\begin{array}{l}\text { CÍRCULO DEL } \\
\text { ESTRECHO }\end{array}$ & $\mathrm{T}-8.2 .1 .1$ & 8 & 11,9 & 350-200 a.C. \\
\hline $\begin{array}{c}\text { CENTRO- } \\
\text { MEDITERRÁNEA }\end{array}$ & $\mathrm{T}-5.2 .3 .2$ & 3 & 4,5 & s. III a.C. \\
\hline PÚNICO-EBUSITANA & $\mathrm{T}-8.1 .2 .1 \circ \mathrm{T}-8.1 .3 .2$ & 1 & 1,5 & $240-120$ a.C. \\
\hline \multicolumn{2}{|l|}{ TOTAL } & 12 & $17,40 \%$ & \\
\hline \multicolumn{5}{|c|}{ VAJILLA FINA DE MESA } \\
\hline \multirow{4}{*}{$\begin{array}{c}\text { ÁTICA FR } \\
-9 \%\end{array}$} & Cratera de campana & 3 & 4,5 & s. IV a.C. \\
\hline & Cratera de columnas & 1 & 1,5 & ss. V-IV a.C. \\
\hline & Escifo & 1 & 1,5 & 425-325 a.C. \\
\hline & Copa de pie bajo & 1 & 1,5 & 375-350 a.C. \\
\hline \multirow{5}{*}{$\begin{array}{l}\text { ÁTICA BN } \\
-9 \%\end{array}$} & L. 21 & 1 & 1,5 & s. IV a.C. \\
\hline & L. 22 & 1 & 1,5 & s. IV a.C. \\
\hline & Cuenco & 2 & 3 & s. IV a.C. \\
\hline & L.23 & 1 & 1,5 & s. IV a.C. \\
\hline & Copa Cástulo & 1 & 1,5 & $450-375$ a.C. \\
\hline \multirow{4}{*}{$\begin{array}{c}\text { TALLER DE ROSES } \\
-9 \%\end{array}$} & L.21 & 1 & 1,5 & $325-200$ a.C. \\
\hline & L.27 & 1 & 1,5 & 325-200 a.C. \\
\hline & L. 36 & 1 & 1,5 & 325-200 a.C. \\
\hline & L. 40 & 3 & 4,5 & $325-200$ a.C. \\
\hline \multirow{3}{*}{$\begin{array}{c}\text { CAMPANIENSE A } \\
\text { ANTIGUA }\end{array}$} & L. 27 & 6 & 9 & 220-180 a.C. \\
\hline & L.23 & 4 & 6 & 220-180 a.C. \\
\hline & L.36 & 3 & 4,5 & 220-180 a.C. \\
\hline \multirow[t]{5}{*}{$-32,80 \%$} & L.31 & 1 & 1,5 & $220-180$ a.C. \\
\hline & Morel 68 & 4 & 6 & 220-180 a.C. \\
\hline & Morel 49B & 1 & 1,5 & $220-180$ a.C. \\
\hline & Guttus & 2 & 3 & 220-180 a.C. \\
\hline & Cuenco ind. & 1 & 1,5 & $220-180$ a.C. \\
\hline \multirow{3}{*}{$\begin{array}{c}\text { PÚNICO EBUSITANA } \\
-7,50 \%\end{array}$} & L.23 & 3 & 4,5 & s. III a.C. \\
\hline & L.28 & 1 & 1,5 & s. III a.C. \\
\hline & Cuenco ind. & 1 & 1,5 & s. III a.C. \\
\hline BYRSA 401 & L. 27 & 1 & 1,5 & 200-130 a.C. \\
\hline KUASS & L.21/25 & 1 & 1,5 & s. III a.C. \\
\hline \multicolumn{2}{|l|}{ TOTAL } & 47 & $70,50 \%$ & \\
\hline \multicolumn{5}{|c|}{ CERÁMICA DE COCINA } \\
\hline PÚNICO EBUSITANA & Olla/cazuela (FE-13/284 o 286) & 1 & 1,5 & s. III a.C. \\
\hline \multicolumn{5}{|c|}{ OTROS } \\
\hline PÚNICA & Ungüentario & 4 & 6 & s. III-II a.C. \\
\hline INDET. & Lucerna & 3 & 4,5 & - \\
\hline \multicolumn{2}{|l|}{ TOTAL } & 7 & $10,50 \%$ & \\
\hline \multicolumn{2}{|c|}{ TOTAL } & 67 & $100 \%$ & \\
\hline
\end{tabular}

Fig. 3: Cuadro-resumen de las importaciones del Sector G de La Serreta.

sido superada por la bibliografía posterior pero que sigue siendo bastante utilizada y resulta fácilmente reconocible. En otros casos, como por ejemplo las copas, se opta por la denominación dada por Morel $(1965 ; 1981)$ o las normalizadas en el Dicocer (1993) como iremos viendo. Al tratarse de producciones en masa, de carácter estandarizado 
Cerámicas importadas del Sector G de La Serreta (Alcoi-Cocentaina-Penàguila). REPERTORIO, DISTRIBUCIÓN Y COMENSALIDAD EN UNA CIUDAD CONTESTANA

y ampliamente estudiadas, trataremos de no profundizar en exceso en cuestiones técnicas o tipológicas con el fin de aligerar el texto.

\section{LAS ÁNFORAS}

Iniciamos nuestro análisis del repertorio con las ánforas cuyo valor para las comunidades locales no estaría tanto en el propio recipiente sino en su contenido. Todos los individuos que hemos identificado en este sector son de origen púnico, posiblemente relacionados con el transporte de salazones, aunque con procedencias diversas. El tipo más abundante es el conocido como T-8.2.1.1. (Ramon 1995: 225-226) con ocho individuos (fig. 4, 1-8) que tienen su origen en el denominado Círculo del Estrecho, en la costa atlántica de Cádiz o en otros puntos de la costa andaluza, con una cronología amplia que iría desde mediados del s. IV hasta finales el III a.C. En nuestro caso, y al tratarse de fragmentos de gran tamaño y en un caso un ejemplar casi completo, corresponderían con bastante seguridad a la última fase del poblado del s. III a.C. Este tipo se ha documentado también en otras áreas del oppidum como los dos individuos del Sector F (Grau 1996: 86-87) así como en otros poblados de la zona datados en el s. IV a.C. como El Puig (Grau y Segura 2013) o La Bastida de les Alcusses (Bonet y Vives-Ferrándiz 2011) y en otros casos con una datación menos precisa como El Castell de Cocentaina, L'Arpella (Grau 2002: 166) o El Pitxòcol (Amorós 2015).

El siguiente tipo identificado es el que tradicionalmente se ha denominado como Mañá $\mathrm{D}$, aunque en nuestros ejemplares podríamos concretar un poco más, ya que se asemejan por su forma al tipo T-5.2.3.2. (Ramon 1995: 199) con tres individuos (fig. 4, 10-12). Este tipo de ánforas tendrían un origen centro-mediterráneo y para este tipo concreto en el área costera de Túnez, aunque resulte difícil de precisar ya que no contamos con ningún individuo completo, solo fragmentos de borde. Se trata de recipientes que se datan en el último tercio del s. III a.C. y no son demasiado abundantes en el área contestana, exceptuando los casos del Tossal de Manises y posiblemente La Escuera (Sala Sellés 1998: 36 y 42).

Finalmente, se identifica un ejemplar bastante completo de ánfora púnico-ebusitana correspondiente bien al tipo T-8.1.3.1. (PE-16) o T-8.1.3.2 (PE-17) (Ramon 1995 223-224) ya que carece de la parte del cuello y el borde (fig. 4, 9), datándose en todo caso entre el 240 y el 120 a.C. Este tipo de ánforas producidas en la isla de Ibiza es algo más común en la franja litoral como es el caso del Tossal de Manises, La Escuera (Sala Sellés 1998: 36 y 42), Dénia, Xàbia, Cap Negret, La Vila Joiosa o el Tossal de la Cala (Ramon 1995: 642-643).

\section{VAJILLA FINA DE MESA}

Continuamos con la valoración del conjunto mayoritario de objetos que son los que podríamos catalogar como vajilla fina de mesa, en su mayoría de barniz negro, aunque también contamos con algunas cerámicas de pasta gris ebusitana. Las agrupamos, por producciones y tipos funcionales como son cuencos y platos, por un lado, y copas y vasos para beber por otro.

\section{CERÁMICA ÁTICA}

Dentro de este conjunto, encontramos dos tipos de producciones, las de figuras rojas y las de barniz negro. Las primeras están representadas por tres crateras de campana (fig. 5, 1, 3 y 4), que por sus características se datan en el s. IV a.C.; un fragmento de asa de cratera de columnas con una cronología del s. V o inicios del IV a.C. (fig. 5, 2); una base de escifo que podría corresponder al tipo Pintor del Fat Boy (fig. 5, 9) y una copa de pie bajo del Pintor de Viena 116, bien datadas ambas en el segundo cuarto del s. IV a.C. (fig. 5, 8). En cuanto al barniz negro, se identifica un fragmento de cuenco L.21; otro de L.22 (fig. 5, 5); dos bases de cuencos indeterminados; un perfil completo de un plato de pescado L.23 (fig. 5, 6), todo ello datado en el s. IV a.C., y un fragmento de asa de una posible Copa Cástulo (L.42A) con una cronología entre el 450 y el 375 a.C. (fig. 5,7 ). Se trata de restos muy fragmentarios que no se han tenido en cuenta en la distribución, ya que no es posible asociarlos directamente a las estructuras del s. III a.C. Asimismo, son tipos que se encuentran con relativa frecuencia en los asentamientos del s. IV a.C. en la zona (García Martín y Grau 1997; García Martín 2004), siendo también el grupo mayoritario en la necrópolis (Cortell et al. 1992; Sala Sellés 1998: 30).

\section{CERÁMICA DE LOS TALLERES DE ROSES}

Otro grupo representado es un conjunto de cerámicas de barniz negro cuyo centro de producción se hallaba en el entorno de la colonia griega de Rhode en el golfo de Rosas (Girona) (Principal y Ribera 2013: 130-137). Estas cerámicas empiezan a producirse ya a finales del s. IV a.C. aunque su presencia empieza a ser más frecuente a inicios del s. III a.C. Sustituyen a las cerámicas áticas protagonistas 
IvÁN Amorós LóPEZ

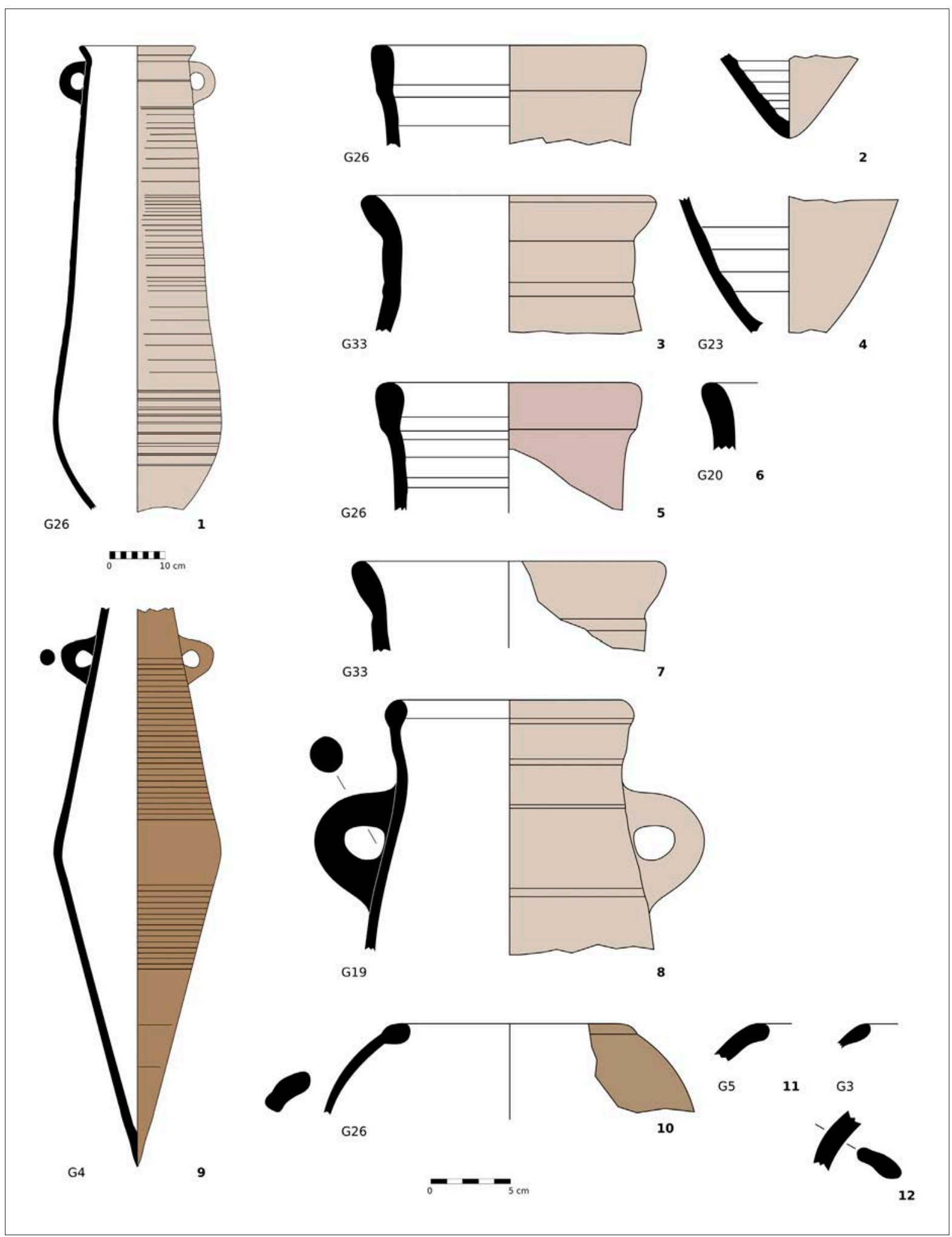

Fig. 4: Ánforas importadas. 1-8. T-8.2.1.1.; 9. PE-16/17; 10-12. T-5.2.3.2. 
Cerámicas importadas del Sector G de La Serreta (Alcoi-Cocentaina-Penàguila). REPERTORIO, DISTRIBUCIÓN Y COMENSALIDAD EN UNA CIUDAD CONTESTANA

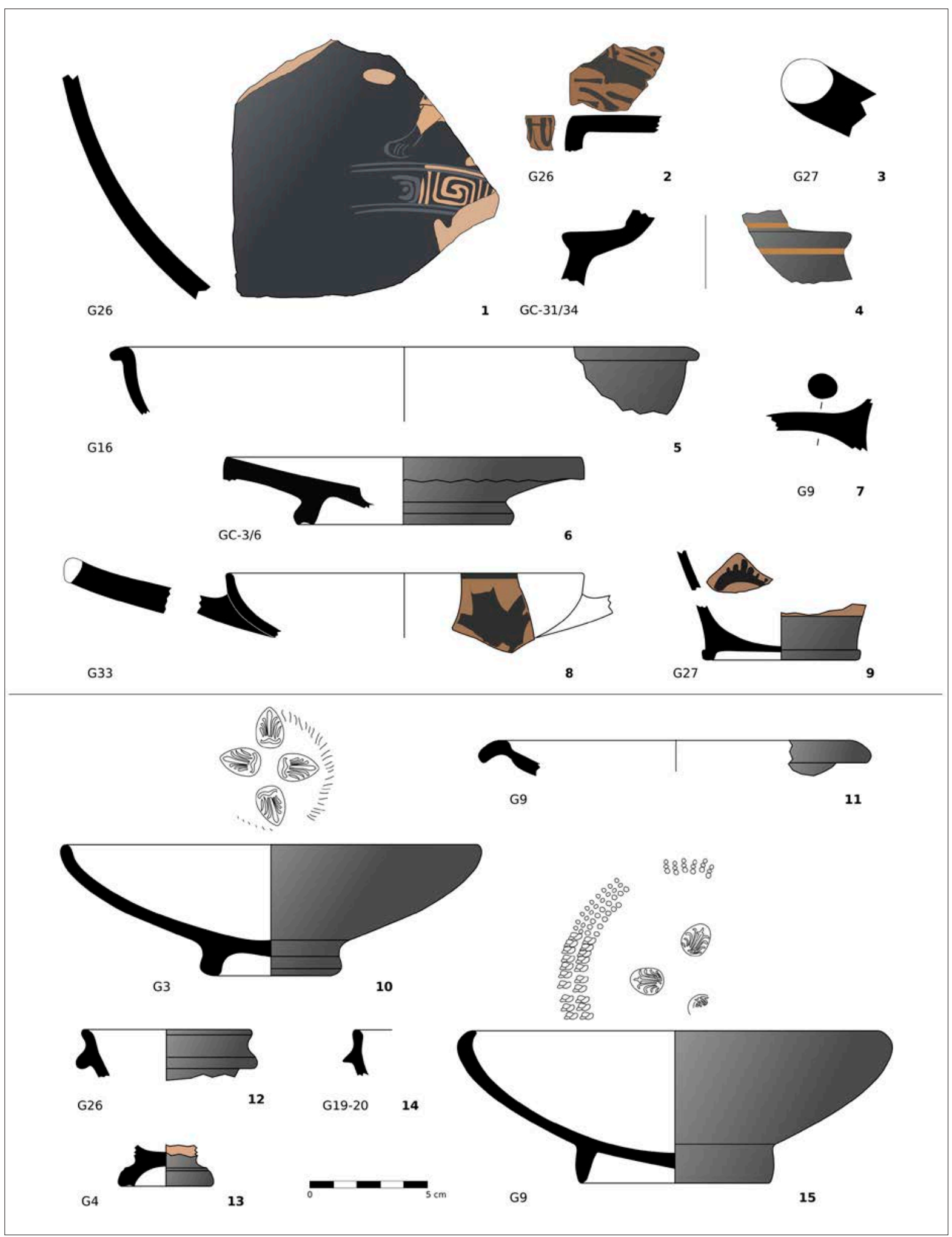

Fig. 5: Cerámicas áticas: 1, 3 y 4. Crateras de campana; 2. Cratera de columnas; 5. L.22; 6. L.23; 7. Copa Cástulo; 8. Copa de pie bajo; 9. Escifo; Cerámicas del Taller de Roses: 10 y 15. L.27; 11. L.36; 12-14. L.40. 
en la centuria anterior, aunque mucho menos numerosas y cuyas formas imitan en los primeros momentos. Se mantendrán hasta finales del s. III a.C. predominando formas más similares a las del tipo Campaniense A.

En el Sector G contamos con seis individuos pertenecientes a esta producción, lo que constituye un $9 \%$ del total de las importaciones. Entre las formas se identifica un cuenco L.21 con decoración de tres palmetas y ruedecilla (fig. 5, 15); un cuenco L.27 con decoración de cuatro palmetas y ruedecilla (fig. 5, 10); un borde de plato L.36 (fig. 5, 11) y tres cántaros distintos de la forma L.40, que se distinguen de los ejemplares áticos por el barniz y el perfil más estilizado del borde (fig. 5, 12-14).

Estas cerámicas de Roses se han identificado también entre los fondos antiguos del poblado, con dos páteras del taller de las Tres Palmetas Radiales, mientras que en la necrópolis se documenta un cuenco L.27; un guttus agallonado con pitorro en forma de cabeza de león; un cuenco L.28; un cuenco L.26 y un fondo de pátera del taller Pi-Alfa-Ro (Sala Sellés 1998: 32). No se trata de materiales especialmente abundantes en el ámbito comarcal, aunque sí se encuentran en La Covalta con un cuenco L.27, un cántaros L.40 y varios indeterminados (Vall de Pla 1971; Bonet y Mata 1998: 245), o en El Castell de Penàguila (Grau 2002: 170), aunque esta escasez podría deberse a la ausencia de un número suficiente de contextos excavados del s. III a.C. En las zonas más próximas a la costa se dan en lugares como La Malladeta (Rouillard et al. 2014: 108-110 y 115-116) o Cap Negret (Sala Sellés 1997).

\section{CERÁMICA CAMPANIENSE A}

Estas cerámicas producidas en la zona del Golfo de Nápoles son las más abundantes tanto en el repertorio analizado, donde constituyen casi el 32,8\% del total de las importaciones, como en el resto de contextos estudiados del poblado. Atendiendo a la buena calidad del barniz y a las formas representadas, podríamos adscribir nuestro conjunto a la fase antigua, datada aproximadamente entre el 220 y el 180 a.C. (Principal y Ribera 2013: 113).

La forma más frecuente es el cuenco L.27 del que se han identificado seis individuos sin que se conserve ningún perfil completo, por lo que resulta difícil establecer la variante a la que corresponden (fig. 6, 8-14). En cuanto a las decoraciones, se documenta una base con tres palmetas impresas conservadas y ruedecilla, mientras que otras tres presentan una roseta central. A continuación, con cuatro individuos, se halla el plato de pescado L.23, uno de ellos completo (fig. 6, 4-7), el plato L.36 con tres individuos, dos de ellos prácticamente enteros (fig. 6, 1-3) y el perfil completo de un cuenco profundo L.31 con decoración sobrepintada blanca en forma de círculos concéntricos y banda en su interior (fig. 7, 5). Cerramos el conjunto de cuencos y platos con una base indeterminada.

Respecto a los vasos para beber, la forma más común es la copa del tipo Morel 68 representada por cuatro ejemplares (fig. 7, 1-4), uno de ellos casi completo y con decoración sobrepintada blanca en forma de círculos concéntricos y banda en la cara interna. También se ha identificado la mitad inferior de una copa del tipo Morel 49B (fig. 7, 6). Para finalizar, hemos decidido incluir aquí dos pequeños fragmentos pertenecientes a sendos gutti aunque estrictamente no puedan ser tratados como vajilla de mesa, pero que creemos que podrían incluirse dentro de las producciones neapolitanas. Queda la duda, por el alto grado de fragmentación, de si podría tratarse de un producto relacionado con los talleres de Roses. Se trata de un fragmento de pico vertedor (fig. 7, 7), así como otro correspondiente a una cazoleta con perforaciones (fig. 7, 8).

Se trata además de la producción más abundante en otros contextos estudiados del poblado como el Sector F, donde se identificaron cuatro individuos L.27, un plato L.36 y una copa Morel 68 (Grau 1996: 84-86), así como un cuenco L.27 en el departamento 3 del Sector B (Abad 1983: 179). Uno de los conjuntos más interesantes es el recuperado en la puerta oriental cuyo material importado está compuesto íntegramente por cerámicas de este tipo con dos cuencos L.27; un plato L.36; un plato L.23; dos copas Morel 68 y una copa Morel 49B (Llobregat et al. 1995: 148). Por otro lado, también es la producción mayoritaria en el Sector I con cinco individuos, dos de ellos del tipo L.27 (Olcina et al. 2000: 127).

Este tipo de productos también es bastante frecuente a nivel regional hallándose tanto en oppida como El Pitxòcol (Amorós 2015), El Xarpolar (Grau y Amorós 2014), El Castell de Cocentaina o el Castell de Penàguila, así como en asentamientos secundarios como El Terratge, La Condomina, Els Ametllers, El Pic Negre o L'Alcavonet (Grau 2002: 170).

\section{CERÁMICA EBUSITANA}

A continuación, entramos a valorar las producciones de origen púnico que tienen un peso bastante significativo entre las importaciones del s. III a.C. en La Serreta, especialmente las de la isla de Ibiza que suponen un 7,5\% del total de los productos importados y que se datarían en 
Cerámicas importadas del Sector G de La Serreta (Alcoi-Cocentaina-Penàguila). REPERTORIO, DISTRIBUCIÓN Y COMENSALIDAD EN UNA CIUDAD CONTESTANA
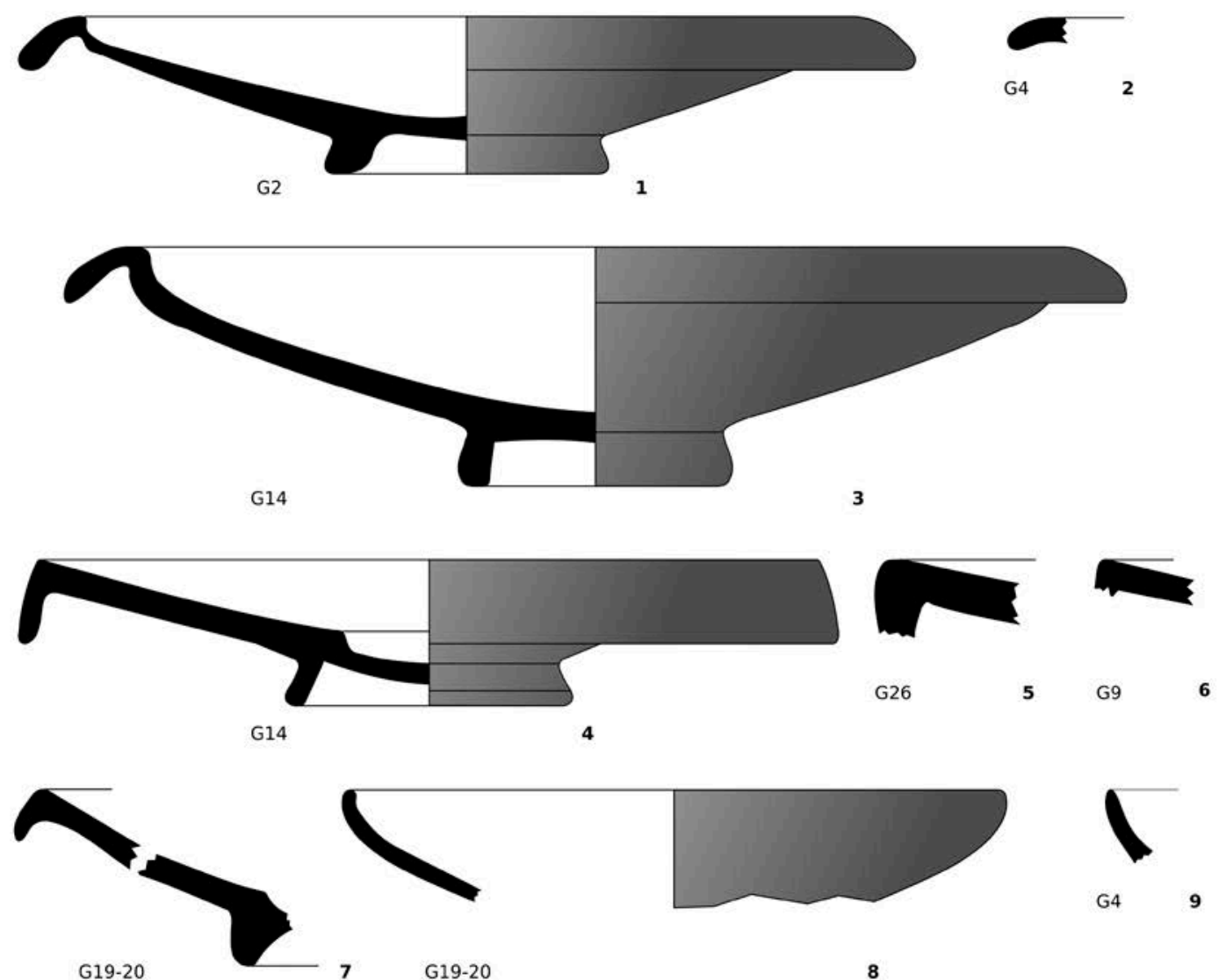

-19-20

G19-20

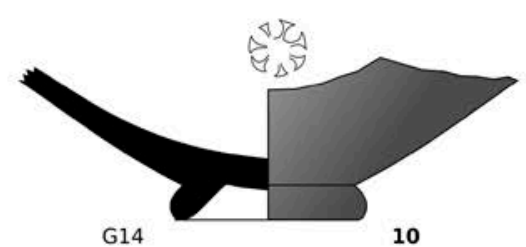

8
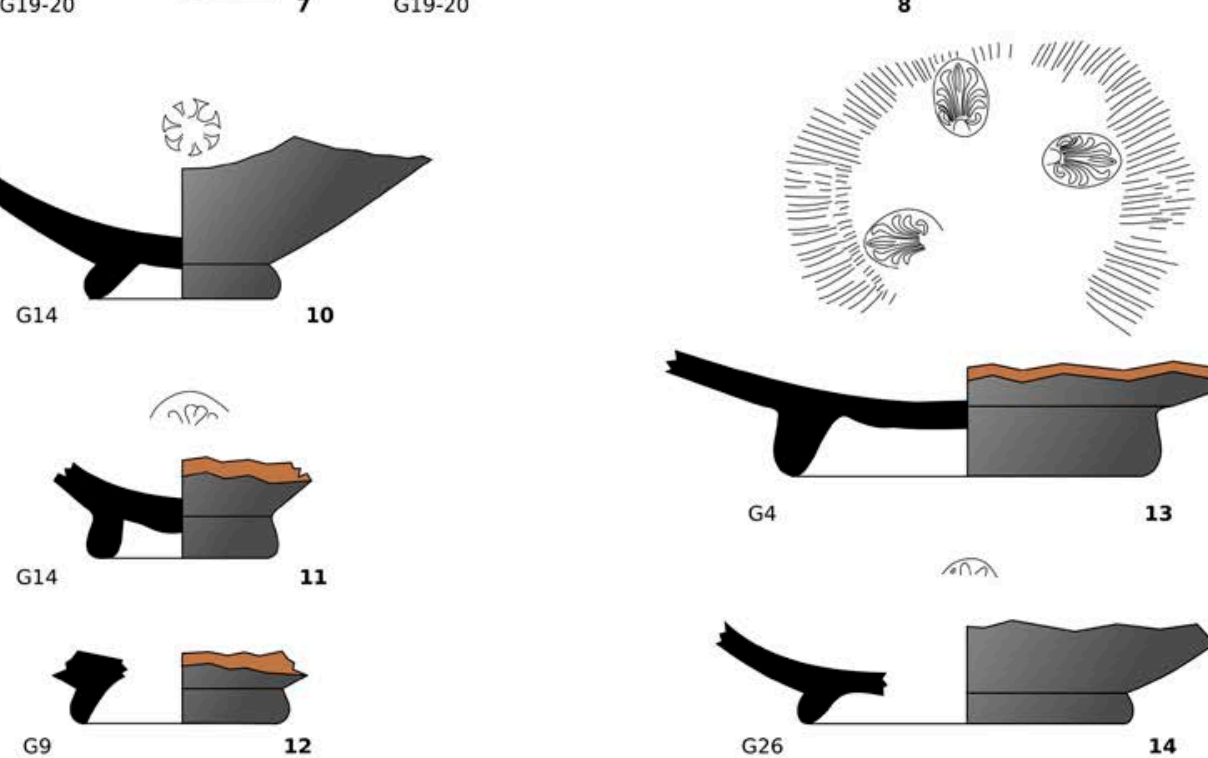

11
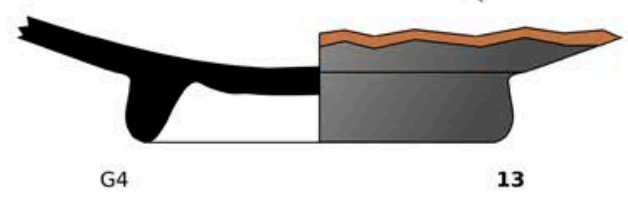

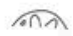

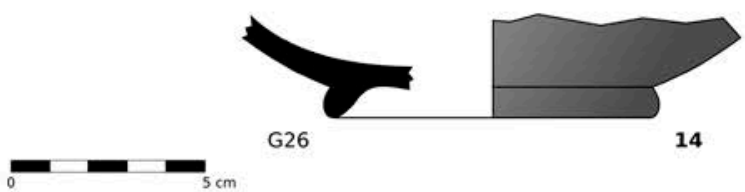

Fig. 6: Cerámica campaniense A: 1-3. L.36; 4-7. L.23; 8-14. L.27. 


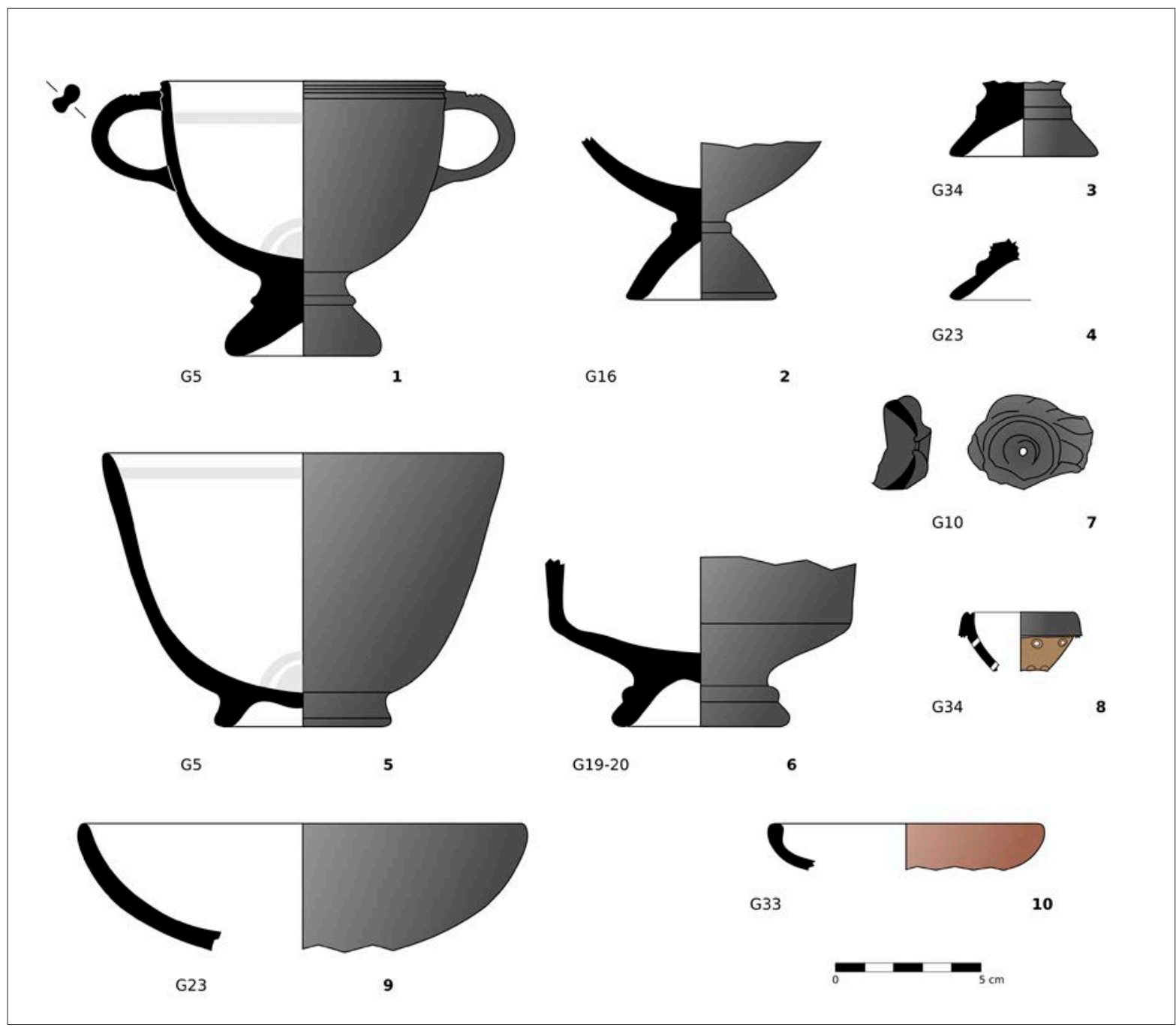

Fig. 7: Cerámica campaniense A: 1-4. Morel 68; 5. L.31; 6. Morel 49B; 7-8. Gutti; Cerámica del Grupo Byrsa 401: 9. L.27; Cerámica Tipo Kuass: 10. L. $21 / 25$.

el s. III a.C. (Ramon 2012). Identificamos dos tipos de productos en el Sector G, por un lado, un plato de pescado L.23 de cocción oxidante y un engobe muy diluido que trata de imitar el barniz negro con una adherencia muy irregular (fig. 8, 5). Por otro, se reconocen las cerámicas de cocción reductora y cubierta exterior de color gris, sin barniz, de la que se documentan dos platos L.23, uno de ellos con una decoración de palmetas geométricas muy esquemáticas (fig. 8,1-2), un cuenco de perfil angular muy similar a la forma L.28 (fig. 8,4$)$ y la base anillada de un cuenco indeterminado (fig. 8, 5).

Estas producciones púnico-ebusitanas se han hallado también en La Covalta (Vall de Pla 1971; Bonet y Mata 1998: 245), El Xarpolar (Grau y Amorós 2014), el Tossal de
La Malladeta, donde constituyen el grupo mayoritario (Rouillard et al. 2014: 108-110 y 115-116) o en la necrópolis de l'Albufereta (Verdú 2015: 158-162).

OTRAS PRODUCCIONES PÚNICAS: BYRSA $401 Y$ KUASS

Dentro de este tipo de cerámicas poco comunes, se identifica un fragmento de borde de cuenco similar a la forma L.27 (fig. 7, 9) y que podríamos adscribir a las producciones del Grupo "Byrsa 401” con una característica pasta amarillenta y un barniz muy poco adherente. Se trata de una cerámica cartaginesa con probable origen siciliano y una cronología entre el 200 y el 130 a.C. (Principal y Ribera 2013: 122-124), escasamente documentada 
Cerámicas importadas del Sector G de La Serreta (Alcoi-Cocentaina-Penàguila). REPERTORIO, DISTRIBUCIÓN Y COMENSALIDAD EN UNA CIUDAD CONTESTANA

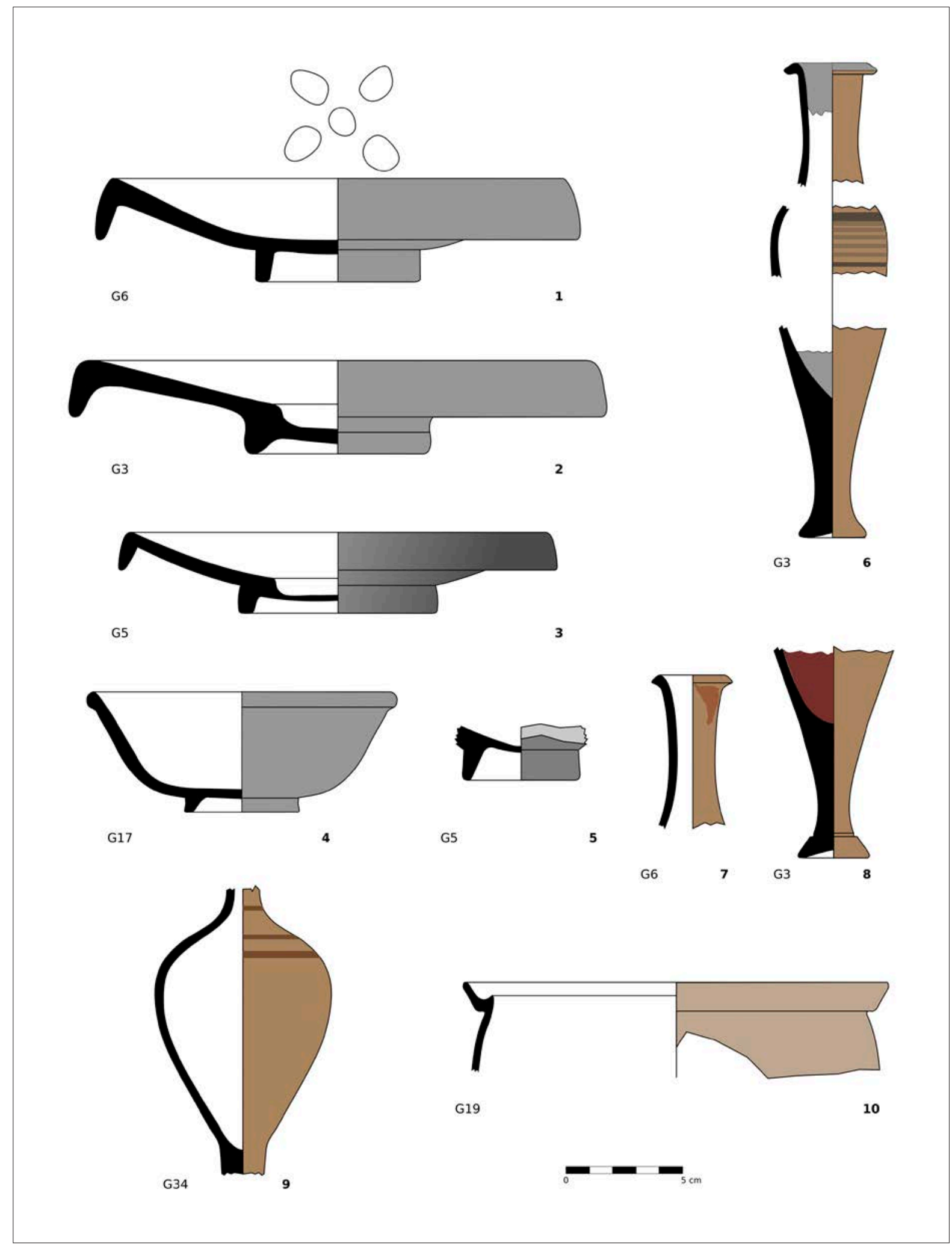

Fig. 8: Cerámicas ebusitanas: 1-3. L.23; 4. L.28; 5. Cuenco; 6-9. Ungüentarios; 10. FE-13/284 o 286. 
y detectada en Valentia (Escrivà et al. 1992), los Villares (Bonet y Mata 1998), La Escuera (Sala Sellés 1998) o la necrópolis de l'Albufereta (Verdú 2015: 162) en el ámbito oriental peninsular.

Otra producción no demasiado común es la de tipo Kuass, cuyo centro productor principal cabría situarlo en la Bahía de Cádiz y se dataría en el s. III a.C. (Niveau de Villedary 2008). Contamos con un borde con el característico barniz rojo y correspondiente a la forma IX-B que imita claramente al tipo L.21/25 ático (fig. 7, 10), cuya cronología podría encajar más en la etapa inicial entre finales del s. IV e inicios del s. III a.C. Aparte de en La Serreta, donde se identifica algún ejemplar más entre los fondos antiguos del poblado y en la necrópolis (Sala Sellés 1998: 32), se documenta en otros asentamientos del ámbito regional como Covalta (Vall de Pla 1971; Bonet y Mata 1998), La Malladeta (Rouillard et al. 2014) o en necrópolis como l'Albufereta (Verdú 2015: 157-158).

\section{CERÁMICA DE COCINA}

La importación de cerámica de cocina suele ser, en general, muy escasa entre las comunidades ibéricas. En nuestro repertorio solo contamos con un fragmento de borde perteneciente a una olla (FE-13/284) o a una cazuela (FE-13/286) de origen púnico-ebusitano con una cronología del s. III a.C. (Ramon 2012: 602) (fig. 8, 10). Este tipo de forma no se ha identificado en el resto de sectores del poblado, aunque sí podríamos englobar dentro de este grupo de las cerámicas comunes, dos morteros, uno de pasta clara massaliota del Sector F (Grau 1996: 87) y otro de origen púnico centro-mediterráneo del Sector I (Olcina et al. 2000: 128). Se ha registrado una cazuela del mismo tipo en la necrópolis de l’Albufereta (Verdú 2015: 163).

\section{UNGÜENTARIOS Y LUCERNAS}

Dentro de este grupo incluimos dos tipos que en principio no se relacionan de forma directa con prácticas de consumo de alimentos y que podrían funcionar como contenedores de productos preciados, tales como aceites o perfumes, o con prácticas rituales como son los ungüentarios y las lucernas. Respecto al primero de los tipos contamos con cuatro ejemplares del tipo fusiforme o B3 de Cuadrado (1977-1978) que se datan genéricamente entre los ss. III y II a.C. (Huguet y Ribera 2013). Uno de los casos presenta restos de un engobe de color gris en la zona del labio, cara interna de la boca y en el fondo, así como restos de pintura gris en forma de bandas en la parte del hombro (fig. 8, 6). En otro caso, el engobe de color rojo se distribuye de forma irregular por la parte externa del labio y el cuello (fig. 8,7 ) mientras que un tercer pie presenta restos de barniz rojo bastante denso en el fondo interno (fig. 8, 8). A pesar de que la pasta se asemeja bastante a la ibérica, estos engobes se alejan de las técnicas alfareras locales, exceptuando el caso del cuarto ejemplar con decoración de dos bandas pintadas que sí podría ser una producción local (fig. 8, 9).

Existen numerosas dudas acerca de la procedencia de este tipo de ungüentarios, aunque parece que debieron existir diversos talleres, posiblemente muy vinculados al ámbito púnico e incluso a la propia Ibiza (Sala Sellés 1995: 205), lo cual sería verosímil atendiendo al relativo peso de las importaciones púnico-ebusitanas entre la vajilla del Sector G. Por otra parte, esta forma está muy vinculada al mundo funerario con una abundante presencia en necrópolis como l'Albufereta (Verdú 2015: 163-167) o El Cigarralejo (Cuadrado 1977-1978), siendo menos comunes en los poblados. Dentro de este grupo podríamos incluir otro extraño recipiente de barniz negro que parece una versión tardía de los lécitos áticos en la estancia B3, donde también se halló un pie de ungüentario fusiforme con restos de barniz en el interior (Abad 1983).

Finalmente, hemos podido identificar la existencia de tres lucernas, dos de ellas de pasta gris y otra de pasta anaranjada, pero en tal estado de fragmentación que resulta difícil ir más allá. Se trata de una forma que sí se encuentra en otro sector como es el ejemplar de lucerna helenística de barniz rojo del tipo Ricci D, datada a finales del s. III a.C. y origen norteafricano, en el departamento F1 (Grau 1996: 86). Este tipo de lucernas se identifican también en el llamado templo del Tossal de Sant Miquel (Bonet 1995: 390) o en el Departamento 1 del Puntal dels Llops (Bonet y Mata 2002: 40) espacios de carácter ritual al igual que el departamento F1.

\section{DISTRIBUCIÓN DE LAS IMPORTACIONES EN EL SECTOR G}

Tras una primera parte más descriptiva, pasamos a la interpretación y comenzaremos con el análisis de la distribución de las cerámicas importadas en el conjunto de manzanas que constituyen el Sector G. Se tienen en cuenta los individuos datados en el s. III a.C., descartando las 


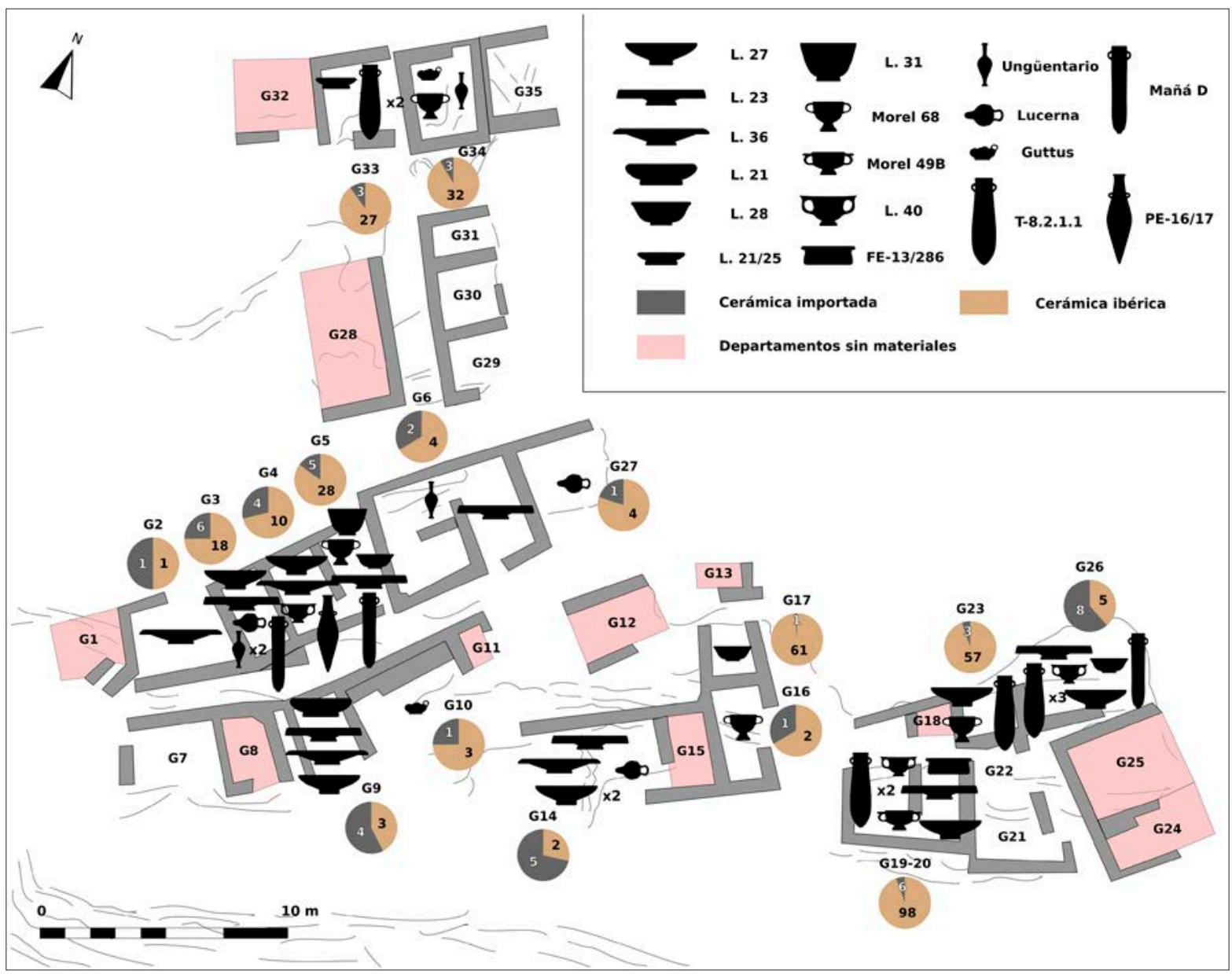

Fig. 9: Plano de distribución de las cerámicas importadas en el Sector G y proporciones con respecto a la cerámica ibérica.

cerámicas áticas por corresponder a una fase anterior y que, por tanto, su asociación con las estructuras conservadas no es segura. Asimismo, no solo se consideran las importaciones de forma aislada, sino que, aprovechando la revisión de todo el conjunto de materiales, se ha establecido la relación porcentual entre las cerámicas importadas y las locales en cada uno de los departamentos, aunque todo el conjunto será objeto de una publicación más detallada en un futuro.

Si vamos de lo general a lo particular, debemos explicitar cuál es la muestra de la que partimos para nuestro análisis. Los materiales cerámicos revisados para los 35 departamentos del Sector $\mathrm{G}$ los conforman 67 individuos importados, que suponen un $15,2 \%$ del total, frente a 373 individuos de cerámica ibérica, un $84,8 \%$. En una primera aproximación al plano de distribución (fig. 9) y atendiendo únicamente a un criterio de presencia/ausencia vemos como estos materiales se distribuyen por un número bastante alto de departamentos (17 de 35, en torno a un $48 \%$ ). Esta proporción aumenta si tenemos en cuenta que, de las 19 estancias restantes, 11 están completamente vacías, con lo que la proporción sería de 17 de 24, casi un $71 \%$. Por tanto, podríamos afirmar que estos objetos no constituyen un bien privativo y exclusivo de una sola familia, aunque si lo observamos todo un poco más de cerca, veremos a continuación cómo es posible apreciar algunos matices. Trataremos de ir describiendo e interpretando en la medida de lo posible tanto las presencias como las ausencias.

La concentración más llamativa es la que se da en las estancias 3, 4 y 5, con 15 individuos que suponen una media del $23 \%$ con respecto a las cerámicas ibéricas y con una cierta variedad tipológica que incluye ánforas, platos, cuencos, copas, ungüentarios y una lucerna. 
Este conjunto presenta además otros elementos diacríticos uno de ellos muy relacionado con la comensalidad como es un rallador de bronce (Grau y Reig 2002-2003: 119) y dos jarros trilobulados con ojos. Esta alta densidad de materiales contrasta con lo que vemos en las estancias 2, 6 y 27, con una superficie mayor, y que quizá se deba a una cierta complementariedad en cuanto a sus funciones dentro de una misma manzana.

Una situación muy diferente es la que se da en la manzana al otro lado de la calle donde las unidades de vivienda no se adosan, sino que se encuentran separadas unas de otras. Es significativa la ausencia de materiales importados en el departamento 7 donde en cambio sí hay otros elementos interesantes relacionados con la comensalidad como una llamativa enócoe profusamente decorada con motivos vegetales (Fuentes 2006: 64). En el departamento 9, a pesar de no existir una alta concentración de materiales, sí vemos como la proporción de importaciones resulta significativa, así como la naturaleza singular de las cerámicas ibéricas como son un jarro con ojos o un fragmento informe con decoración figurada compuesta por un jinete a caballo (Fuentes 2006: 64). Finalmente, en la estancia 10 se identifica un solo fragmento, aunque poco frecuente, de guttus, de nuevo en un espacio con poca concentración de materiales.

Pasando a la siguiente manzana, en el departamento 14 observamos una concentración bastante importante de materiales importados que además se asocian a dos fragmentos con decoración compleja y que pertenecerían a un gran recipiente del tipo tinaja (Fuentes 2006: 66). En las estancias 16 y 17 no se dan concentraciones importantes.

En el conjunto más oriental del sector, se halló un elevado y variado número de objetos importados en los departamentos 19-20 con ánforas, un plato, un cuenco, copas y la única cerámica de cocina, pero que queda diluido en la enorme concentración de materiales en este punto, donde destaca no solo la gran acumulación de tinajas, sino también de vajilla de mesa y cocina. En el centro de este conjunto, se da una ausencia significativa de importaciones en los departamentos 21-22, posiblemente un espacio de trabajo caracterizado por la ausencia general de cerámicas. Al $\mathrm{N}$ del conjunto se encuentra la estancia 23, donde la presencia de las importaciones también se enmarca en una gran acumulación de cerámica ibérica. La situación inversa la encontramos en el departamento 26 donde se da el número más alto de individuos importados en una sola estancia (ocho) y donde destacan cuatro ánforas.
Para ir finalizando este recorrido por el sector $\mathrm{G}$, debemos señalar la ausencia significativa de importaciones en las estancias 29-31, donde por otra parte no se da una gran acumulación de materiales. Finalmente, nos centramos en las estancias situadas al norte de la calle central del poblado, en dos de la cuales se da una cierta concentración de materiales en superficies no demasiado amplias, aunque no es el caso de las importaciones. En el departamento 33 se identifican dos ánforas y un cuenco junto con un conjunto muy variado de cerámica ibérica. Por su parte, la estancia 34 resulta una de las más interesantes del sector más allá de las importaciones, que son bastante escasas, pero donde hay un variado repertorio de cerámica ibérica. En la estancia 35 no se documenta ninguna importación, aunque los materiales en general son muy escasos.

Las primeras conclusiones que se desprenden de este análisis espacial es que se trata de un barrio, a priori formado por contextos de carácter doméstico, caracterizado por una cierta homogeneidad entre las distintas viviendas, sin grandes diferencias arquitectónicas, y donde se distribuyen de forma amplia los bienes importados sin seguir un patrón claramente centralizado. Ello no implica, sin embargo, que no existan ciertas diferencias entre las distintas estancias.

\section{LAS IMPORTACIONES EN OTROS SECTORES DE LA SERRETA}

Como se ha señalado al inicio del trabajo, resulta muy difícil hablar de amplias distribuciones espaciales en el poblado de La Serreta más allá del Sector G, pero sí merece la pena prestar atención a algunos contextos interesantes como la estancia B3, el sector F y más concretamente el departamento F1, las habitaciones del Sector I y la puerta oriental del poblado.

El primer contexto doméstico que vamos a analizar es la estancia B-3 cuyo repertorio material fue valorado en detalle por L. Abad (1983). Se trata de una estancia excavada por C. Visedo en el año 1953 en la vertiente meridional del cerro con unas dimensiones aproximadas de 3,60 x 2,40 $\mathrm{m}$ y una superficie de $8,64 \mathrm{~m}^{2}$ que podría ser algo mayor ya que no se conserva el muro de cierre $\mathrm{S}$. En este departamento, que podemos considerar de carácter doméstico se documentó un lote de piezas cerámicas que incluye tanto importaciones de barniz negro como producciones ibéricas. Entre las cerámicas importadas se 
Cerámicas importadas del Sector G de La Serreta (Alcoi-Cocentaina-Penàguila). REPERTORIO, DISTRIBUCIÓN Y COMENSALIDAD EN UNA CIUDAD CONTESTANA

encuentra una pieza excepcional como es una pátera con umbillicus de forma semiesférica y decorada con relieves hechos a molde cuya procedencia es calena. También se identifica un bol de campaniense A de la forma L.27 y un recipiente de barniz negro difícil de catalogar, aunque podría ser una especie de lekythos de la serie 5410 de Morel y un ungüentario (Abad 1983: 185). Se trata de un conjunto compuesto por cuatro ejemplares de cerámica importada que constituyen el $36 \%$ del total y siete ejemplares de cerámica ibérica que suponen el 64\% restante.

Por otra parte, en el Sector F en su conjunto aparecen pocas importaciones si tenemos en cuenta su extensión, entre ellas cuatro cuencos L.27, un plato L.36, una copa Morel 68, una lucerna, dos ánforas T-8.2.1.1. y un mortero, que suponen un 5,3\% del total del repertorio (Grau 1996). Especialmente interesante en este sector resulta la estancia F1, aislada del resto de departamentos de este barrio y que por la concentración de numerosas piezas singulares se ha interpretado como un espacio de carácter sacro que se aleja de los ámbitos domésticos que hemos estado viendo hasta ahora (Grau 1996; Grau et al. 2008). Las cerámicas importadas asociadas a este espacio son un cuenco L.27, un plato L.36 y una lucerna tipo Ricci D, una forma muy poco común, y que constituyen el $7 \%$ del total. El resto del repertorio cerámico lo forman 42 individuos de cerámica ibérica de almacenaje (tinajillas, $\mathrm{ka}$ lathoi, lebetes, tinajas y ánforas), algunos de ellos con una decoración pintada excepcional como el conocido Vas dels Guerrers o el kalathos de la paloma entre otros. A ello habría que añadir otros elementos tan poco comunes como el conjunto de terracota de la Diosa Madre o la matriz y el bloque de plomo asociados a la orfebrería.

Otro contexto bien estudiado en La Serreta son las dos estancias que formarían parte de una misma vivienda ubicada en el Sector I en la vertiente meridional del cerro que fue excavado ya con metodología científica en el año 1995 (Olcina et al. 2000). Se trata de dos departamentos de unos 2,5 x 2 m adosados a la pared de roca de la vertiente de la montaña y cuyo muro de cierre meridional se ha perdido completamente, lo que nos impide conocer las dimensiones reales de la vivienda que no serían mucho mayores y que contaría además con una planta superior. En el departamento $\mathrm{O}$ se hallaron cuatro ejemplares de cerámica de importación representados por tres recipientes de cerámica campaniense $\mathrm{A}$, dos de ellos cuencos del tipo L.27ab, y otro recipiente de origen caleno que constituyen el 13,8\% del total del repertorio. En cuanto a cerámica ibérica se documentan 25 ejemplares que suponen el
$86,2 \%$. Por otra parte, en el departamento E aparecieron tres recipientes de cerámica de importación como son dos cuencos de campaniense A y un mortero de origen púnico que constituyen el 37,5\% del total del repertorio. La cerámica ibérica está representada por cinco ejemplares que suponen el $62,5 \%$ restante. En este caso, solo se ha excavado una única vivienda dentro de este sector, lo que nos impide una perspectiva más amplia.

Finalmente, queremos destacar otro contexto singular como es el conjunto de materiales hallados bajo la puerta de entrada al poblado y depositados en algún tipo de ritual, que podríamos relacionar con prácticas de comensalidad, con motivo de su construcción a finales del s. III a.C. (Llobregat et al. 1995). Se encontraron diversas piezas de barniz negro del tipo Campaniense A como son un asa de copa Morel 49B, dos platos, uno del tipo L.23 y otro L.36, dos cuencos L.27 y una copa Morel 68. Entre la cerámica ibérica se identifican distintas formas como ánforas, ollas, platos y jarras entre las que destaca una enócoe con decoración figurada de carácter guerrero, así como tres figurillas de terracota, una de rostro realista, otra cabeza esquemática y restos de un grupo.

En el resto del poblado, se dan, por tanto, unas pautas similares a las del Sector $\mathrm{G}$ caracterizadas por la ausencia de grandes concentraciones y de un patrón centralizado respecto a los objetos importados. Asimismo, predominan los contextos de carácter doméstico, aunque vemos como su valor diacrítico le otorga un papel importante en dos espacios con un claro componente ritualizado como son la estancia F1 o la puerta oriental.

También resulta interesante establecer una comparación, necesariamente breve, con la situación que nos encontrábamos en los poblados del s. IV a.C. en este mismo ámbito geográfico con un buen ejemplo en el caso de El Puig d'Alcoi (Grau y Segura 2013). En cuanto a su distribución, estos elementos importados se encuentran en todas las áreas excavadas, pero con matices restrictivos referentes por ejemplo a elementos diacríticos, como las crateras o los grandes recipientes de figuras rojas, que en La Serreta no se han tenido en cuenta por ser un contexto del s. III a.C., y porcentajes variables en relación con la cerámica ibérica que van desde el 6 al 23\% dependiendo de las casas. Sí parece que la llegada de productos importados durante el s. IV a.C. es mayor, ya que en El Puig se han contabilizado para esta centuria 156 individuos para una superficie excavada comparable al Sector $\mathrm{G}$ frente a los 55 individuos datados en el s. III a.C. que componen nuestra muestra. Esta diferencia se hace aún más palpable 
si lo comparamos con poblados con grandes superficies excavadas como La Bastida de les Alcusses con miles de individuos. También a nivel de prospección parecen existir menos evidencias de importaciones en el s. III a.C. si lo comparamos con el s. IV a.C. (Grau 2002; Amorós 2019b), aunque es cierto que las importaciones de esta fase son algo más difíciles de caracterizar y reconocer. No obstante, somos conscientes de que múltiples variables podrían influir en estos números, tales como la técnica de excavación, la superficie excavada o el área elegida dentro del poblado, por lo que esta propuesta comparativa tendría un valor meramente aproximativo.

\section{A MODO DE CONCLUSIÓN. EL VALOR SOCIAL DE LAS VAJILLAS IMPORTADAS EN EL S. III A.C.}

Llegados a este punto creemos necesario valorar este tipo cerámicas importadas en su contexto social, en otras palabras, el papel que pueden estar jugando en la articulación de las relaciones sociales y de poder entre los distintos grupos que habitaron el poblado de La Serreta en el s. III a.C. En este sentido, cobra una especial importancia el concepto de comensalidad, así como las posibles estrategias ideológicas derivadas de estas prácticas.

La primera de las conclusiones es que observamos un patrón descentralizado, con una amplia distribución de estos bienes por la mayoría de los departamentos, aunque con ciertos matices, sin que existan tampoco diferencias arquitectónicas relevantes entre las distintas viviendas. Este hecho nos puede estar indicando que los grupos dominantes ibéricos no concentran tanto poder en sus manos como para controlar sin fisuras el acceso a este tipo de bienes de prestigio, algo característico de sociedades de tipo heterárquico como creemos que es la ibérica (Bonet et al. 2015; Grau y Vives-Ferrándiz 2018). Asimismo, esta pauta reflejaría la voluntad de estas elites, que son las que tienen acceso tanto a los excedentes como a los canales de intercambio de este tipo de piezas, de redistribuirlas entre sus grupos clientelares o dependientes con el objetivo de generar una tupida red de intereses basada en la existencia de deudas y favores. Un ejemplo de esa dialéctica entre estrategias ideológicas corporativas y excluyentes que hemos propuesto para diversas prácticas rituales entre las sociedades ibéricas (Amorós 2019a).

Sin embargo y como ya se ha visto en el apartado correspondiente, existen concentraciones más significativas que otras como la que se produce en los departamentos 3 ,
4 y 5 . Esta concentración en determinadas estancias y la ausencia en otras dentro de una misma manzana, podría estar reflejando que la gestión de estas estrategias relacionadas con la comensalidad y determinadas prácticas rituales quizá estuvieron en ciertos casos centralizadas y gestionadas en una institución social suprafamiliar. Estas estrategias ideológicas cobran sentido en una sociedad heterárquica con un poder disperso y organizada en unidades sociales como linajes, facciones o Casas que compiten entre sí (Bonet et al. 2015).

Una diferencia importante con respecto a la fase anterior del s. IV a.C. es la menor variedad en el repertorio de la vajilla de mesa donde predominan los cuencos $(42 \%)$, seguidos de los platos (33\%) y finalmente las copas (25\%). Observamos una cierta homogeneidad si lo comparamos con las importaciones áticas donde era posible establecer una mayor gradación debido a la existencia de un número más variado de elementos diacríticos como los grandes recipientes de preparación y servicio (crateras, ánforas, pélices o enócoes), con el valor añadido de estar decorados en muchos casos con figuras rojas. Cabe la posibilidad de que la función de este tipo de recipientes de preparación y servicio sea sustituida por objetos locales ante la falta de oferta de estos tipos en los centros de producción itálicos y púnicos. Entre esos objetos podríamos citar los grandes recipientes de almacenamiento con decoración figurada o narrativa, que en realidad no abundan en el Sector G, los lebetes de muy diversos tamaños que sí encontramos en la mayoría de las estancias, y los jarros o enócoes cuya abundancia en el repertorio también es significativa. Dentro de esta última forma, queremos destacar los llamados jarros con ojos que aparecen en las estancias 4, 5 y 9 y cuya importancia en este tipo de prácticas ritualizadas ha sido valorada en la Edetania desde una perspectiva muy interesante (Vives-Ferrándiz y López-Bertran 2017).

Debido a esta relativa homogeneidad formal del repertorio, resulta algo más difícil establecer asociaciones vasculares significativas dentro de los distintos departamentos o aproximarse a la escala de participación. Partimos de la premisa de que no estamos ante un depósito primario que refleje directamente la celebración de un ágape, sino ante los objetos guardados en los espacios domésticos, aunque quizá sea posible una aproximación al número de potenciales comensales a partir de un objeto de uso individual como serían las pequeñas copas para beber. Estas se distribuyen de forma bastante regular por las distintas manzanas con un número total de nueve 
Cerámicas importadas del Sector G de La Serreta (Alcoi-Cocentaina-Penàguila). REPERTORIO, DISTRIBUCIÓN Y COMENSALIDAD EN UNA CIUDAD CONTESTANA

frente a 23 platos y cuencos, algunos de los cuales podrían ser de uso individual y otros para compartir. Un número hipotético de comensales en torno a esta cifra resulta plausible si tenemos en cuenta el número de familias que pudo habitar este barrio y que no todos sus miembros tendrían acceso a estos banquetes, o al menos en las mismas condiciones.

Mientras que en la fase anterior la distinción recae no tanto en el producto sino en la forma de consumirlo, es decir, el vino local consumido en vajillas foráneas, en estos momentos parece cobrar una mayor importancia el consumo de salazones púnicas, como indicaría el considerable volumen de ánforas importadas. La relevancia de las salazones podría estar también relacionada con la mayor presencia de platos L.23, cuya forma estaba concebida originalmente para el consumo combinado de salsas y alimentos como la carne o el pescado. Por otra parte, el vino y sus propiedades embriagadoras seguirían ocupando un lugar privilegiado en dichos banquetes, como se deduce de la presencia de copas para beber, una preferencia de las comunidades ibéricas que se observa desde el Hierro Antiguo hasta el Ibérico final. Normalmente, el vino no se consumiría puro sino mezclado con agua, hierbas aromáticas o incluso queso rallado como indican las fuentes clásicas, prácticas con las que podrían relacionarse otros elementos de preparación ya citados como los morteros importados de los sectores F e I (Grau 1996: 87; Olcina et al. 2000: 128) o el rallador de bronce del departamento 3 (Grau y Reig 2002-2003: 119).

Los contextos de aparición de este tipo de cerámicas en el Sector G parecen de carácter doméstico, aunque suponemos que reservadas para ocasiones especiales más allá del consumo cotidiano. La reducida superficie de las estructuras no favorecería el desarrollo de grandes banquetes en su interior, sino que estos podrían tener lugar en los numerosos espacios abiertos que en general existen por todo el poblado y más concretamente alrededor de este barrio. Sí hay constancia de la importancia de estos objetos en contextos mucho más ritualizados dentro del poblado como la estancia F1 o el ritual realizado con motivo de la construcción de la puerta de entrada.

$\mathrm{Si}$ atendemos a las categorías de banquete establecidas por Dietler (2001) se asemejan bastante a los del tipo empowering o incluso patron-role feast donde se manipula la hospitalidad comensal con el objetivo de adquirir prestigio, crédito social, influencia o poder por parte del organizador, generando al mismo tiempo sentimientos de deuda social hacia los anfitriones, que en muchas ocasiones compiten entre sí. Durante el s. III a.C., asistimos en La Serreta y su territorio al surgimiento de un modelo que podríamos considerar en ciertos aspectos como ciudadano, donde en muchos ámbitos se inhiben claramente las prácticas ostentosas o de clara diferenciación social (Amorós 2019a). Se mantiene, por tanto, una apariencia de igualdad que no es real, ya que la desigualdad radica en que solo los líderes de las distintas facciones tendrían acceso a estos productos y vajillas que luego distribuyen entre sus clientelas. Estos miembros de la elite serían además los poseedores de los escasos elementos diacríticos que se identifican en esta fase y relacionados con la preparación y servicio de los alimentos, como las cerámicas ibéricas con decoración compleja, el rallador de bronce, los morteros o la patera calena con relieves, que les otorgarían un rol preeminente en el desarrollo de los banquetes.

Finalmente, es importante también poner en valor la agencia de las comunidades locales, alejándonos de una perspectiva colonialista donde las poblaciones iberas son meros agentes pasivos. Debemos tener en cuenta que no existe una uniformidad en las dinámicas relacionadas con estos bienes importados que podamos extender a todo el ámbito ibérico, más bien al contrario. Se ha podido constatar en otros trabajos, desde una perspectiva diacrónica más amplia, la existencia de estrategias diferentes dependiendo del territorio en que nos encontremos, a veces muy próximos entre sí (Amorós 2019a; 2019b). Un buen reflejo de esta diversidad se puede encontrar en la otra gran ciudad de la franja central mediterránea como es el Tossal de Sant Miquel, que experimenta, en muchos sentidos, procesos sociales similares a los de La Serreta durante el s. III a.C. En este caso, entre los ajuares en uso en el momento inmediatamente anterior a la destrucción del poblado, datada en el primer cuarto del s. II a.C., no solo no hay un gran volumen de producciones del s. III a.C., sino que el $50 \%$ es vajilla ática del s. IV a.C. que ha perdurado (Bonet 1995: 394), ya que se encuentran completas y no demasiado fragmentadas como en nuestro caso. Del mismo modo que no existe el mismo interés por el consumo de salazones como indica la ausencia de ánforas púnicas o de un número significativo de platos de pescado. Creemos que la explicación a estas pautas debemos buscarla en los intereses y preferencias de las comunidades locales, ya que estas poblaciones edetanas se encuentran en condiciones similares en cuanto al acceso al mercado de este tipo de productos. 
En definitiva, a lo largo de estas páginas, hemos tratado, por un lado, de presentar de forma detallada un conjunto cerámico que se une de esta forma al corpus existente para las cerámicas importadas del s. III a.C. en la Contestania. Por otro, hemos podido asociar este interesante repertorio a determinadas estructuras y contextos materiales en una superficie bastante amplia como es el Sector G. Desde aquí, reivindicamos la necesidad de seguir publicando de la forma más detallada posible los contextos, con el objeto de conformar una base sólida sobre la que apoyar nuestras interpretaciones, por otra parte, absolutamente necesarias. El análisis de este barrio, ubicado además en una ciudad que actuó como capital de un importante territorio político de escala comarcal, nos ha permitido valorar la importancia de este tipo de objetos en sus contextos de uso con un papel destacado en la articulación de las relaciones sociales entre los distintos grupos que compondrían una comunidad ibérica del s. III a.C. en las montañas contestanas.

\section{AGRADECIMIENTOS}

Quiero agradecer al personal del Museu Arqueològic Camil Visedo de Alcoi, Josep Maria Segura, Palmira Torregrosa y Josep H. Miró, su amabilidad y las facilidades a la hora de acceder a los materiales. Asimismo, quisiera dar las gracias a los doctores Ignasi Grau y Jaime Vives-Ferrándiz, así como a los evaluadores anónimos de la revista, por la revisión del texto y sus siempre valiosas aportaciones que, sin duda, han contribuido a enriquecerlo y mejorarlo.

\section{BIBLIOGRAFÍA}

ABAD, L. (1983): Un conjunto de materiales de La Serreta de Alcoy, Lucentum II, 173-197. DOI: https://doi.org/10.14198/LVCENTVM1983.2.08

AMORÓS, I. (2015): Secuencia de ocupación del poblado ibérico de El Pitxòcol (Balones, Alicante) a partir de su repertorio material, Alberri. Quaderns d'Investigació del Centre d'Estudis Contestans 25, 133-169.

AMORÓS, I. (2019a): Ideología, poder y ritual en el paisaje ibérico. Procesos sociales y prácticas rituales en el área central de la Contestania, Trabajos Varios. S.I.P. 123, València.

AMORÓS, I. (2019b): Las prácticas de comensalidad como estrategia ideológica en el área central de la Contestania ibérica (VII-I a.C.), Zephyrus LXXXIV, 41-62. DOI: https://doi.org/10.14201/zephyrus2019844162

ARCELIN, P.; TUFFREAU-LIBRE, M. (dirs.) (1998): La quantification des céramiques, conditions et protocole, Actes de la table ronde du Centre archéologique européen du Mont Beuvray (Glux-enGlenne, 7-9 avril 1998), Centre archéologique européen du Mont Beuvray, Glux-en-Glenne.

BONET, H. (1995): El Tossal de Sant Miquel de Llíria. La antigua Edeta y su territorio, València.

BONET, H.; GRAU, I.; VIVES-FERRÁNDIZ, J. (2015): Estructura social y poder en las comunidades ibéricas de la franja central mediterránea, Arqueo Mediterrània 14, 251-272.

BONET, H.; MATA, C. (1998): Las cerámicas de importación durante los siglos III y principios del II a.C. en Valencia, Les fàcies ceràmiques d'importació a la costa ibèrica, les I. Balears $i$ les Pitiuises durant el segle III aC $i$ la primera meitat del segle II aC (J. Ramon et al., eds.), Arqueo-Mediterrània 4, Barcelona, 49-73.

BONET, H.; MATA, C. (2002): El Puntal dels Llops. Un fortín edetano, Trabajos Varios. S.I.P. 99, València.

BONET, H.; VIVES-FERRÁNDIZ, J. (eds.) (2011): La Bastida de les Alcusses. 1928-2010, València.

CORTELL, E.; JUAN, J.; LLOBREGAT, E.; REIG, C.; SALA, F.; SEGURA, J. M. (1992): La necrópolis ibérica de La Serreta: Resumen de la campaña de 1987, Estudios de Arqueología Ibérica y Romana: Homenaje a Enrique Pla Ballester, Trabajos Varios. S.I.P. 89, València, 83-116.

CUADRADO, E. (1977-1978): Ungüentarios cerámicos en el mundo ibérico: aportación cronológica, Archivo Español de Arqueología 50-51, 389-404.

DICOCER (1993): Dictionnaire des Céramiques Antiques (7ème s. av.n.è - 7ème de n.è) en Méditerranée nord-occidentale (Provence, Languedoc, Ampurdan), Lattes.

DIETLER, M. (1999): Rituals of commensality and the politics of state formation in the princely societies of early Iron Age Europe, Les princes de la Protohistoire et l'émergence de l'état (P. Ruby, ed.), Roma, 135-152. DOI: https://doi.org/10.4000/books.pcjb.303

DIETLER, M. (2001): Theorizing the feast. Rituals of consumption, commensal politics, and power in African contexts, Feasts. Archaeological and Ethnographic perspectives on food, politics, and power (M. Dietler, B. Hayden, eds.), Washington y Londres, 65-114.

DIETLER, M.; HAYDEN, B. (2001): Feasts: Archaeological and Ethnographic Perspectives on Food, Politics and Power, Washington y Londres.

DILOLI, J.; SARDÀ, S. (eds.) (2009): Ideologia, pràctiques rituals $i$ banquet al nord-est de la Península Ibèrica durant la Protohistòria, Tarragona.

ESCRIVÀ, V.; MARÍN, C.; RIBERA, A. (1992): Unas producciones minoritarias de barniz negro en Valentia durante el s. II a. JC, Estudios de Arqueología Ibérica y Romana: Homenaje a Enrique Pla Ballester, Trabajos Varios. S.I.P. 89, València, 442-468.

FUENTES, M. (2006): Propuesta de definición del estilo pictórico de La Serreta (Alcoi, Cocentaina, Penàguila; Alacant), Recerques del Museu d'Alcoi 15, 29-74. 
Cerámicas importadas del Sector G de La Serreta (Alcoi-Cocentaina-Penàguila). REPERTORIO, DISTRIBUCIÓN Y COMENSALIDAD EN UNA CIUDAD CONTESTANA

GARCÍA MARTÍN, J. M. (2004): El comercio de cerámicas griegas en el sur del País Valenciano (siglos VIII al IV a.C.), Tesis doctoral inédita, Universidad Autónoma de Madrid.

GARCÍA MARTÍN, J. M.; GRAU, I. (1997): Les ceràmiques gregues als jaciments ibèrics de l'Alcoià i el Comtat, Recerques del Museu d'Alcoi 6, 119-130.

GODELIER, M. (1998): El enigma del don, Barcelona.

GRAU, I. (1996): Estudio de las excavaciones antiguas de 1953 y 1956 en el poblado ibérico de La Serreta, Recerques del Museu d'Alcoi 5, 83-135.

GRAU, I. (2002): La organización del territorio en el área central de la Contestania Ibérica, Alicante.

GRAU, I.; AMORÓS, I. (2014): Secuencia de ocupación y análisis territorial del poblado ibérico de El Xarpolar (Vall d'Alcalà, Alacant), APL XXX, 239-261.

GRAU, I.; AMORÓS, I.; SEGURA, J. M. (2017): El santuario ibérico y romano de La Serreta (Alcoi, Cocentaina, Penàguila). Prácticas rituales y paisaje en el área central de la Contestania, Alcoi.

GRAU, I.; OLMOS, R.; PEREA, A. (2008): La habitación sagrada de la ciudad ibérica de La Serreta, $A E A$ 81, 5-29. DOI: https://doi.org/10.3989/aespa.2008.v81.38

GRAU, I.; REIG, C. (2002-2003): Sobre el uso de metales en la Contestania ibérica: las evidencias de La Serreta, Recerques del Museu d'Alcoi 11-12: 101-150.

GRAU, I.; SEGURA, J. M. (2013): El oppidum ibérico de El Puig d'Alcoi. Asentamiento y paisaje en las montañas de la Contestania, Alcoi.

GRAU, I.; VIVES-FERRÁNDIZ, J. (2018): Entre casas y comunidades: formas de organización y relación social en el área oriental de la península ibérica (siglos V-II a.n.e.), Más allá de las casas. Familias, linajes y comunidades en la protohistoria peninsular (A. Rodríguez, I. Pavón, D. Duque, eds.), Cáceres, 75-109.

HUGUET, E.; RIBERA, A. (2013): Los ungüentarios, Manual de cerámica romana. Del mundo Helenístico al Imperio Romano (A. Ribera, coord.), Alcalá de Henares, 191-197.

HUSI, P. (2001): Quantification et datation en céramologie (Le nombre minimum d'individus: la technique de quantification la mieux adaptée à la datation des contextes archéologiques à partir de l'exemple de Tours), Les petits cahiers d'Anatole 6, 1-27.

LAMBOGLIA, N. (1952): Per una classificazione preliminare della ceramica campana, Atti del I Congresso di Studi Liguri, Bordighera, 139-206.

LLOBREGAT, E. (1972): Contestania Ibérica, Alicante.

LLOBREGAT, E.; CORTELL, E.; JUAN, J.; OLCINA, M.; SEGURA, J. M. (1995): El sistema defensiu de la porta d'entrada del poblat ibèric de La Serreta. Estudi preliminar, Recerques del Museu d'Alcoi 4, 135-162.

LLOBREGAT, E.; CORTELl, E.; JUAN, J.; SEGURA, J. M. (1992): El urbanismo ibérico en La Serreta, Recerques del Museu d'Alcoi 1,37-70.
MATA, C.; PÉREZ JORDÀ, G.; VIVES-FERRÁNDIZ, J. (eds.) (2010): De la cuina a la taula.IV Reunió d'Economia del primer mil·lenni, Saguntum-PLAV Extra-9, València.

MOREL, J. P. (1965): Céramique à vernis noir de Pompéi, RCRF 7 , 81-103.

MOREL, J. P. (1981): Céramique campanienne: les formes, BEFAR 244, Paris.

NIVEAU DE VILLEDARY, A. M. (2008): La cerámica Tipo Kuass, Cerámicas hispano-romanas. Un estado de la cuestión (D. Bernal y A. Ribera, eds.), Cádiz, 245-262.

OLCINA, M.; GRAU, I.; MOLTÓ, S. (2000): El Sector I de La Serreta: noves perspectives sobre l'ocupació de l'assentament, Recerques del Museu d'Alcoi 9, 119-144.

OLCINA, M.; GRAU, I.; SALA, F.; MOLTÓ, S.; REIG, C.; SEGURA, J. M. (1998): Nuevas aportaciones a la evolución de la ciudad ibérica: el ejemplo de La Serreta, Actas del Congreso Internacional Los Iberos, príncipes de Occidente. Las estructuras de poder en la sociedad ibérica (C. Aranegui, ed.), Saguntum-PLAV Extra-1, València, 35-46.

ORTON, C.; TYERS, P.; VINCE, A. (1997): La cerámica en Arqueología, Barcelona.

PRINCIPAL, J.; RIBERA, A. (2013): El material más apreciado por los arqueólogos. La cerámica fina. La cerámica de barniz negro, Manual de cerámica romana. Del mundo Helenístico al Imperio Romano (A. Ribera, coord.), Alcalá de Henares, 41-146.

RAMON, J. (1995): Las ánforas fenicio-púnicas del Mediterráneo central y occidental, Col·lecció Instrumenta 2, Barcelona.

RAMON, J. (2012): La cerámica púnico-ebusitana en época tardía (siglos III-I a.C.), Cerámicas hispanorromanas II. Producciones regionales (D. Bernal y A. Ribera, eds.), Cádiz, 584-617.

ROUILLARD, P.; ESPINOSA, A.; MORATALLA, J. (2014): Villajoyosa Antique (Alicante, Espagne). Territoire et topographie. Le sanctuaire de la Malladeta, Madrid.

SALA SELLÉS, F.. (1995): La cultura ibérica de las comarcas meridionales de la Contestania entre los siglos VI y III aC, Alicante.

SALA SELLÉS, F. (1997): Memoria de las excavaciones en el poblado ibérico de Cap Negret (Altea, Alicante). La intervención de urgencia de 1987, Memoria depositada en la Conselleria de Cultura de la Generalitat Valenciana.

SALA SELLÉS, F. (1998): Los problemas de caracterización del siglo III a.C. en los yacimientos de la Contestania, Les fàcies ceràmiques d'importació a la costa ibérica, les I. Balears $i$ les Pitiuises durant el segle III aC. i la primera meitat del segle II aC. (J. Ramon et al., eds.), Barcelona, 29-48.

SANMARTÍ, J. (2009): From the archaic states to romanization: a historical and evolutionary perspective on the Iberians, $\mathrm{Ca}$ talan Historical Review 2, 9-32.

SANMARTÍ, J.; ASENSIO, D. (2017): Pottery imports and social organization. Theoretical-methodological principles, and a case of study of the 4th century BC in the Iberian coast, Homenaje a Glòria Trias Rubiés. Cerámicas griegas de la 
Península Ibérica: cincuenta años después (1967-2017) (X. Aquilué; P. Cabrera y M. Orfila, eds.), Centro Iberia Graeca, 338-347.

SARDÀ, S. (2010a): Pràctiques de consum ritual al curs inferior de l'Ebre. Comensalitat, ideologia $i$ canvi social (s. VII-VI ane), Tesis Doctoral. Universitat Rovira i Virgili.

TARRADELL, M. (1969): Noticias de las recientes excavaciones de la Universidad de Valencia, Actas del X Congreso $\mathrm{Na}$ cional de Arqueología, Zaragoza, 183-186.
VALL DE PLA, M. A. (1971): El poblado ibérico de Covalta (Albaida, Valencia), Trabajos Varios. S.I.P. 41, València.

VERDÚ, E. (2015): La necrópolis de l'Albufereta (Alacant). Ritos y usos funerarios en un contexto de interacción cultural, Serie Mayor II, Alicante.

VIVES-FERRÁNDIZ, J.; LÓPEZ-BERTRAN, M. (2017): Jarras edetanas con ojos pintados, Homenaje a la profesora Carmen Aranegui Gascó (F. Arasa, C. Mata, eds.), SaguntumPLAV, Extra-19, València, 213-225. 